\title{
LA CAZA DE LIEBRES CON GALGOS EN ANDALUCÍA: DESDE EL CONFLICTO A LA PATRIMONIALIZACIÓN
}

\section{HARE COURSING WITH GREYHOUNDS IN ANDALUSIA: FROM CONFLICT TO PATRIMONIALISATION}

Helena P. Gamuz

Universidad Pablo de Olavide

Pablo Palenzuela Chamorro

Universidad de Sevilla

\section{RESUMEN}

La caza de liebres con galgos en Andalucía es una modalidad de caza menor sin armas de fuego que posee un fuerte arraigo en la región. El colectivo de galgueros y galgueras andaluces, que en la actualidad se aproxima a los seis millares de participantes, entiende que sus prácticas se encuentran en situación de vulnerabilidad debido, principalmente, pero entre otros, a las críticas y discursos que se desprenden desde otros sectores de la población que cuestionan y denuncian la utilización y el trato que aquellos ofrecen a los animales involucrados en esta modalidad cinegética. Este conflicto percibido ha sido uno de los motivos por los cuales se ha promovido la elaboración de un informe técnico para el registro de la actividad en el Atlas del Patrimonio Inmaterial de Andalucía. El mismo entrañaría el reconocimiento, que no la declaración o catalogación con efectos jurídico-administrativos, de la actividad como patrimonio cultural inmaterial y vivo en este territorio. Este artículo presenta, a partir de los resultados extraídos del trabajo 
de campo llevado a cabo para la elaboración de dicho informe, los principales valores etnológicos detectados para la caza de liebres con galgos en Andalucía. A partir de ello, el texto reflexiona sobre cómo el conflicto puede convertirse en catalizador de procesos de patrimonialización, al tiempo que del mismo surgen ciertas problemáticas de índole ético y moral con las actividades y prácticas que se quieren proteger y en las que se utilizan animales.

Palabras clave: Caza de liebres con galgos; Andalucía; Patrimonio inmaterial; Conflicto; Relaciones humano-animales.

\begin{abstract}
Hare coursing with greyhounds in Andalusia is a modality of small game hunting without firearms that is deeply rooted in the region. The group of Andalusian greyhound hunters, which currently numbers around six thousand participants, understands that their practices are in a situation of vulnerability, mainly due, among others, to the criticism and discourse coming from other sectors of the population which question and denounce the use and treatment offered to the animals involved in this hunting modality. This perceived conflict has been one of the reasons why it has promoted the drafting of a technical report for the registration of the activity in the Atlas of the Intangible Heritage of Andalusia. This would entail the recognition, but not the declaration, of the activity as intangible and living cultural heritage in this territory. This article presents, based on the results of the fieldwork carried out for the preparation of this report, the main ethnological values detected for hare coursing with greyhounds in Andalusia. On this basis, the text reflects on how the conflict can become a catalyst for heritage processes, while at the same time certain ethical and moral problems arise with the activities and practices that are to be protected and in which animals are used.
\end{abstract}

Keywords: Hare coursing with greyhounds; Andalusia; Intangible heritage; Conflict; Human-animals relations.

\title{
INTRODUCCIÓN
}

La caza de liebres con galgos es una modalidad de caza menor que presenta en Andalucía una larga tradición y arraigo, asociada a la disposición del territorio y su orografía. Se produce ampliamente en los paisajes de campiña y en los socioecosistemas que a ella se vinculan, siendo estos un medio óptimo tanto para la reproducción de la liebre como para el desarrollo de la persecución y captura de las mismas por parte de los galgos. Son las 
grandes extensiones y llanuras de labor de la cuenca baja del río Guadalquivir, un amplio agroecosistema que se extiende desde el norte al sur de Andalucía, donde se asienta el área de influencia galguera. La actividad en sí misma supone la concurrencia de una o varias personas en el territorio acotado para tal fin, en periodo hábil para el ejercicio de la caza, que acompañadas de sus perros lebreles se disponen a pie en búsqueda activa de alguna liebre. Una vez que se identifica esta, los galgueros sueltan a sus canes -solo dos por liebre- para que intenten capturarla y darle muerte antes de que se escape burlando a los perros.

Si bien esta actividad, caracterizada por la no utilización de armas de fuego, supuso en el pasado, especialmente en el segundo tercio del siglo XX, una forma de caza a través de la cual muchas familias jornaleras andaluzas tuvieron algo de suministro cárnico en sus mesas (Romero, 2010), en la actualidad y desde los años setenta, coincidiendo con el "boom cinegético" español (López Ontiveros, 1994), la práctica tomó el cariz de recreativa y deportiva. En este contexto en el cual no es imprescindible "cazar para comer", es donde surgen una serie de disputas y tensiones éticas y morales en torno a la propia actividad y al trato que en ella se les da a los animales involucrados (Robinson y Watkinson, 2020). Los discursos que sobre ella se vierten encuentran una fuerte oposición. De un lado, el colectivo de personas que llevan a cabo la actividad entiende que sus prácticas son, en pocas palabras, respetuosas con el entorno donde se produce y con los animales utilizados, además de que supone una forma muy particular de vincularse con el territorio y de afianzar una solidaridad intra-grupal que compone parte de su identidad como colectivo. De otro lado, se critica fuertemente y se denuncia, principalmente, el abandono y la muerte de los perros utilizados en las carreras, así como la práctica en sí misma, ya que se entiende como un vestigio de un pasado "bárbaro" del cual hay que escapar (Dahles, 1993; Dizard, 1994; Bulliet, 2005).

Con esta oposición y disputa como telón de fondo, el colectivo de galgueras y galgueros andaluces percibe que su actividad puede peligrosamente aproximarme a un callejón sin salida que termine irreversiblemente con la caza de liebres con galgos en la región. Más teniendo en cuenta, según ellos y ellas, la expansión contemporánea de una ideología moderna a favor de los derechos de los animales que no dejan, en cierto modo y paradójicamente, de compartir. En su memoria, además, aparecen otras prácticas históricas y festividades donde la utilización de animales ya fue cuestionada y, finalmente, censurada (Gómez Pellón, 2017). Es por eso que desde el colectivo se entiende que "el futuro del galgo depende de que los galgueros/as sepamos contar nuestra relación con los galgos, parece fácil, pero es muy difícil escribir de cosas intangibles" (Salamanca, 2010: 192). En ese sentido, a principios de 2021, la Federación Andaluza de Galgos, entidad deportiva creada en 1992 y que aglutina de manera formal al colectivo de galgueros y galgueras andaluces, al mismo tiempo que se integra en la Federación Española de 
Galgos, solicita la inclusión del registro "La caza de liebres con galgos en Andalucía" en el Atlas del Patrimonio Inmaterial de Andalucía a través del encargo de un informe técnico de valoración etnológica de la actividad ${ }^{1}$.

El Atlas del Patrimonio Inmaterial de Andalucía fue creado en 2008 como un proyecto de amplia cobertura territorial y funcional, dirigido a la salvaguardia del patrimonio inmaterial de Andalucía mediante acciones de conocimiento, valorización y fomento de dicho patrimonio intangible. Este proyecto del Instituto Andaluz de Patrimonio Histórico pretende establecer las mejores fórmulas de protección del patrimonio cultural inmaterial andaluz, en el sentido amplio que lo entiende la Convención para la Salvaguarda del Patrimonio Inmaterial de la UNESCO de París, de 2003, Art. 2:

"usos, representaciones, expresiones, conocimientos y técnicas -junto con los instrumentos, objetos, artefactos y espacios culturales que les son inherentes- que las comunidades, los grupos y en algunos casos los individuos reconozcan como parte integrante de su patrimonio cultural".

Esta finalidad se consigue a través de medidas dirigidas a la identificación, documentación, investigación, valorización, transmisión y revitalización del patrimonio cultural inmaterial andaluz en sus distintos aspectos. Los procedimientos de puesta en marcha de estas medidas se hacen a partir de una metodología antropológica, con técnicas de trabajo participativas que permitan generar una red de colaboradores que, durante las fases de registro y en el futuro, participen en dichas acciones. En el caso concreto de la actividad social de la caza de liebres con galgos, la elaboración del informe tuvo por objeto la confección de un documento descriptivo y analítico que recogiese el catálogo de valores etnológicos que justificasen, o no, la inclusión en el Atlas del Patrimonio Inmaterial de

1. Este informe técnico estuvo financiado por la Federación Andaluza de Galgos y fue desarrollado a través de la Fundación de Investigación de la Universidad de Sevilla (FIUS), en coordinación con el Instituto Andaluz de Patrimonio Histórico (IAPH). El contrato tuvo una vigencia de cuatro meses (julio-octubre de 2021) y se ejecutó mediante la realización de entrevistas semi-dirigidas a informantes cualificados de las provincias de Huelva, Sevilla, Cádiz, Málaga y Córdoba, así como de observaciones participantes en esos contextos. La dirección del proyecto recayó en el Departamento de Antropología Social de la Universidad de Sevilla, siendo el Investigador Principal Santiago M. Cruzada, integrando el resto del equipo de investigación las firmantes de este texto. 
Andalucía un registro sobre la actividad social, en su versión eminentemente recreativa²

En ese sentido, este texto presenta, en una primera parte, algunos de los resultados más destacados del informe que hemos elaborado para tal fin. En primer lugar, se hace una somera definición histórica de la actividad y su desarrollo en el contexto andaluz, se describe cómo se produce la práctica y cuáles son los cambios que se han venido sucediendo en los últimos años. Igualmente, se esboza la exigua legislación que afecta a la misma y se incide en la problemática actual que tiene la liebre. A continuación, se describe el "universo galguero andaluz", donde se delinea el territorio óptimo para la realización de la actividad y su vinculación con los procesos históricos y socioeconómicos en la región. En tercer lugar, se presentan lo que entendemos son los valores etnológicos más destacados de la actividad: se analizan las relaciones sociales que se producen a partir de la misma, sus formas de organización, y las técnicas y saberes necesarios para desarrollar esta modalidad de caza, incidiendo en las relaciones humano-animales que se vinculan a ella $y$, de manera más amplia, sobre las relaciones humano-ambientales relacionadas. A partir de aquí y en una segunda parte, el texto reflexiona sobre el conflicto como motor y revulsivo para los procesos de patrimonialización. Se analiza el contexto conflictual de la caza de liebres con galgos en Andalucía desde la voz de sus actores, y se ahonda en cuestiones que tienen que ver con el maltrato, abandono y brutalidad con los animales involucrados. Por último, nos aproximamos de manera reflexiva y teórica a las problemáticas y retos de índole ético y moral que emergen con los procesos de patrimonialización de actividades y prácticas en las que se utilizan animales.

\section{DESCRIPCIÓN ETNOGRÁFICA DE LA CAZA DE LIEBRE CON GALGOS EN ANDALUCÍA}

Los galgos en Andalucía y su vinculación a la caza pueden rastrearse desde antes del siglo II a. C., pero es a partir de este momento cuando aparecen los tratados más sustanciales

2. A pesar de no poder trazarse una línea divisoria entre las diferentes modalidades de caza con galgo que existen actualmente, puede considerarse esta versión recreativa como la que alberga con mayor amplitud dichos valores etnológicos. Algunas variantes de la caza de liebre con galgo que hoy en día se consolidan con un gran número de practicantes serían la caza de liebres en competición (indisociable ya de la recreativa), caza de liebres en cercones, "caza" de liebres con bozales puestos a los perros, o carreras de galgos al alcance de liebres mecánicas (estas dos últimas, stricto sensu, no podrían considerarse caza). 
en torno a su práctica. Arriano de Nicomedia, en su obra Cynegheticus (traducción al castellano de 1965), realizó una recopilación y registro de las reglas que debían guiar la cacería en esta modalidad, algunas de las cuales todavía siguen vigentes ${ }^{3}$. Esta práctica habitual en el mundo rural andaluz se practicaba y practica sin exclusión por condición social. Se dice que la caza de liebres con galgos es una "caza de gitanos, jornaleros y señoritos", atravesando nominalmente, aunque no siempre en la práctica, las jerarquías sociales, contrariamente a otras modalidades de caza como pueda ser la montería ${ }^{4}$. Del mismo modo, aunque de forma mayoritaria la actividad está sustentada por hombres, cada vez se observan más mujeres criadoras de galgos y apasionadas por la caza de liebre con galgos ${ }^{5}$. Al no emplear armas de fuego ni ninguna otra clase de instrumentos o tecnologías para la captura de la liebre, esta modalidad se ha mantenido a lo largo de los siglos casi inalterada en su estructura y en sus prácticas, no obstante, existen ciertas modificaciones, como veremos, que se han impuesto con la finalidad de una mejor regulación. La esencia de esta actividad, según sus participantes, consiste precisamente en la medición de fuerzas entre dos animales, la liebre y el galgo, y los cazadores actúan en esos momentos como espectadores de fugaces e impredecibles lances cinegéticos:

"El hombre, cuando caza, se sirve de ardides que merman e inutilizan las defensas de la pieza, pero en la caza con galgos únicamente actúa de espectador. Aquí,

\begin{abstract}
3. Algunas de las reglas que fueron recogidas por Arriano de Nicomedia, y que continúan hoy en día siendo referentes en la práctica, están relacionadas con la suelta de los galgos en el momento que "salta la liebre", la distancia que se le otorga al animal y cuántos perros se pueden soltar simultáneamente, o la identificación de las liebres jóvenes y la prohibición de cazarlas. También sobre la crianza, y el momento óptimo de madurez de galgos machos y hembras, o sobre los terrenos apropiados para la caza, entre otras.
\end{abstract}

4. El carácter interclasista de la caza de liebre con galgos es hoy una realidad. Al no ser necesaria la munición, ni las armas refinadas, el poder adquisitivo del galguero no es determinante para la práctica. En tiempos pasados, como se verá, el galgo era aliado necesario de los jornaleros sin tierra, al tiempo que, paradójicamente, objeto de valor entre la aristocracia que contemplaba sus carreras en competición.

5. Si bien los datos recogidos a través del Instituto Andaluz de Caza y Pesca Continental, en el año 2020, del total de licencias expedidas para la caza sin armas de fuego, en la que se incluye la caza de liebres con galgos, solo un $1 \%$ de las mismas correspondían a mujeres, no deseamos invisibilizar su presencia dentro del colectivo en nuestro discurso porque, como ellas mismas reclaman, "cada vez son más las mujeres que se acercan al galgo, y no hace falta tener un marido para cazar. Yo quiero poder salir al campo sola, con mis perros y que el guarda no tenga que decirme nada” (M.R.C., 51 años, trabajadora del campo, Fuentes de Andalucía). 
como en la altanería, lo que se enfrenta es un animal a otro, un instinto ofensivo a otro defensivo. Lo propio de la liebre es correr. La constitución del galgo le impulsa, asimismo, a la carrera. La espectacularidad de la pugna deriva entonces de la serie de estratagemas que ambos ponen en juego, el uno para prender, la otra para evitar ser prendida" (Delibes, 1989: 6).

El proceder habitual de la práctica y su desarrollo suelen darse desde el amanecer hasta el mediodía, pudiendo esta prolongarse en una segunda incursión en el campo en las tardes, después del almuerzo. Disponiendo cada galguero de su collera de perros, a primera hora se realiza un sorteo para establecer la posición que ocupará su pareja de galgos en la suelta, ya que sólo está permitida la suelta simultánea de dos galgos por liebre ${ }^{6}$. Una vez sobre el terreno que se cazará esa jornada, los galgueros se colocan en línea, separados en torno a dos o tres metros de distancia, formando "la cuerda" o "mano", de manera que avanzan horizontalmente barriendo la mayor extensión del acotado:

Ir en "mano sobre mano" implica guardar rigurosa línea y mirar el suelo, con sigilo. Las cabezas van de pie a pie unos metros por delante de donde se está ahora y donde se estará en unos segundos. La mirada busca a la liebre en el suelo en el tramo de tierra que le corresponde a cada quien, entre aquel de la collera a nuestra derecha $y$ el de nuestra izquierda. Y sin perder la línea, pues al tiempo debemos volver a re-cazar la misma zona en busca de alguna "cama" (lugar donde aguarda parada la liebre) que se le haya escapado al compañero. Los perros tranquilos, o al menos, idealmente tranquilos, pero atentos, sabiendo qué hemos venido hacer. Quien ve la liebre la "canta", es decir, avisa al resto de compañeros, y una vez dispuestos galgos $y$ "traillero" (persona encargada de llevar la "traílla", que es un mecanismo de correa que produce una suelta simultánea de los dos perros que van amarrados) en una posición idónea y más o menos cercana a la liebre, esta se levanta y se la deja correr, mientras los galgos, ahora sí ansiosos y tensos, con los ojos puestos en "la rabona", están listos para la suelta. Con suerte la carrera será lo suficientemente larga como para medir cuán cazador es qué galgo, único can con las aptitudes apropiadas para

\footnotetext{
6. La idoneidad de soltar dos galgos a una liebre resulta de la observación y práctica de los propios galgueros, ya que se estima que esta es la proporción óptima para que en la carrera puedan medirse las capacidades de los perros (si fuesen tres, aseguran, se desvirtuaría la comparación), al tiempo que se limita el escape de la liebre, pues, según dicen, esta resultaría casi siempre vencedora si la persecución se produjese solo con un galgo.
} 
que esta modalidad cinegética se produzca ${ }^{7}$ (Extracto del diario de campo, enero de 2021).

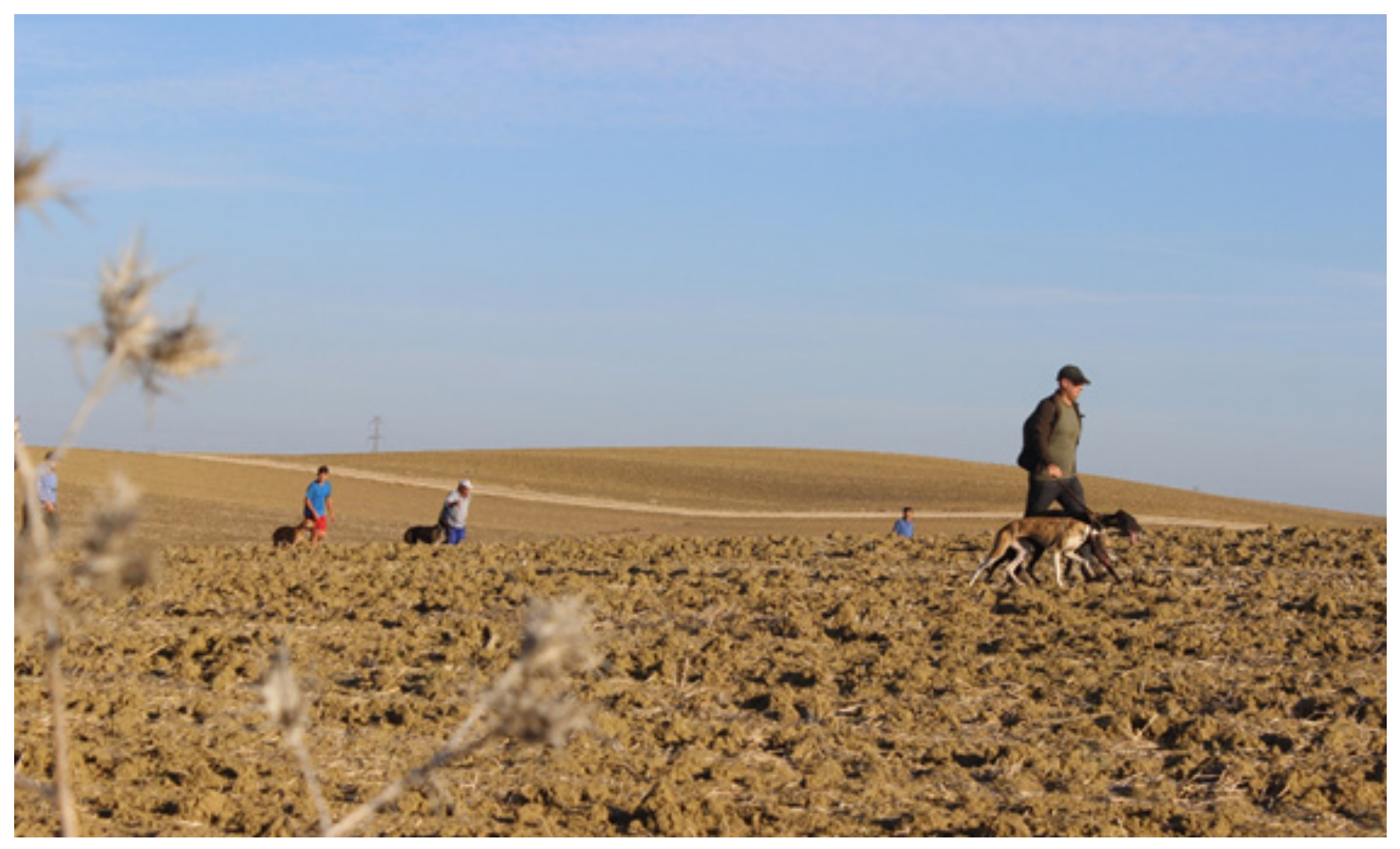

Imagen 1. "Mano" batiendo el terreno. Fuente: Helena P. Gamuz.

La formación de la "mano" depende principalmente del número de galgueros y ojeadores, estos últimos acompañando sin perro a "batir" el terreno. En la parte central de la "cuerda" se sitúan aquellos galgueros con los galgos que serán los primeros en correr, siempre con estos "atraíllados". Los mismos se disponen ligeramente adelantados al resto, siendo quienes, una vez "cantada" la liebre, soltarán a los lebreles, siempre respetando una

7. Se denomina a la liebre "rabona" por su particular rabo blanco y resultón, destacando este entre sus atributos, al igual que sus orejas, por lo cual también se la denomina "orejona”. El "traillero", por su parte, es aquel galguero o galguera que porta a los galgos que correrán la liebre que "salte". Como portador de la "traílla", debe tener, a juicio del grupo, cierta maña en la suelta, pero también sagacidad para analizar el momento del lance, así como a la propia liebre que aparece, es decir, su estado y madurez. Una vez catalogada como "idónea” para ser perseguida, le dará la llamada "ventaja": una distancia prudencial -que dependerá del estado del terreno, o de la dirección que haya tomado la liebre, entre otros factores- que permita una carrera "justa" para la liebre. 
distancia de "ventaja" a juicio del "traillero" para que las carreras -aseguran- sean "justas". Una vez sueltos los perros a la carrera, se jalean y se intenta seguir el paso vertiginosa de la misma, lo que es bastante difícil si no se va a caballo.

A través de esta específica tipología de caza "al salto", en el "encuentro cinegético" que se produce entre la liebre y el galgo -y por extensión con los galgueros- se da una "situación de peligro" (Marvin, 2005) que perturba a la liebre para hacerla salir de su "encame". Los galgueros y galgos "barriendo" el terreno con la exclusiva intencionalidad de "levantar" a la liebre, con ausencia de armas, así como el proceder de esta modalidad, no responde a lo que en otras modalidades cinegéticas -como los "aguardos" o la caza de perdiz con reclamo- se ha denominado "engaño", una ocultación de los seres humanos que generan una trampa perceptiva para el animal cazable (Cruzada, 2019: 164-233). La conceptualización de la caza de liebres con galgos, por ello, se entiende como una de las modalidades de caza "más ecológica", tal como plantean los galgueros, pues, entre otras cuestiones, responde al sentimiento por parte de estos de participar en el mundo en el que la liebre se ve inmersa "en su día a día", y por ello desean no alterar su "defensa natural", que es el correr, y no intervenirla con armas u otros elementos que mermen sus "potencialidades de especie" (Despret, 2013). La ausencia de armas y la carencia de acciones específicamente humanas en el desarrollo de los "encuentros cinegéticos" (a excepción de la regulación de los lances con las "traíllas") sitúa al galguero/a como una especie de observador -según sus propios discursos- quien con fin contemplativo observa la escena, y sólo a través de su vinculación con el galgo, y de manera extendida a las cualidades y capacidades de los mismos, se convierten en cazadores.

El proceder de la caza de liebres con galgos, por ello, continúa desenvolviéndose de la misma manera que siglos atrás, pudiéndose realizar de manera individual o en grupo, aunque es esta última la forma común de cazar en los cotos sociales andaluces. Sin embargo, y a pesar de la estabilidad y continuidad que comentábamos, existen dos factores claves que modificaron sustancialmente la práctica a mediados del siglo pasado: el uso de la "traílla" y el cambio en la finalidad de la práctica. La "traílla", artesanía de cuero que permite soltar dos perros al mismo tiempo, supone un mecanismo regulador de los lances, en los que, a partir de su incorporación, se impuso la participación de dos galgos por cada liebre, fomentando así una caza más selectiva y proteccionista con este animal, en el sentido, particularmente, de poder decidir qué liebre se corre o no, discriminando, por ejemplo, entre liebres viejas y jóvenes -optándose siempre por las primeras-, o si las mismas se encuentran preñadas o afectadas por alguna enfermedad -caso en el que se decide no correrlas.

El segundo elemento clave del cambio en la práctica fue la finalidad con la que se salía al campo a cazar. Hasta finales del siglo XX, la captura de liebres, así como del resto 


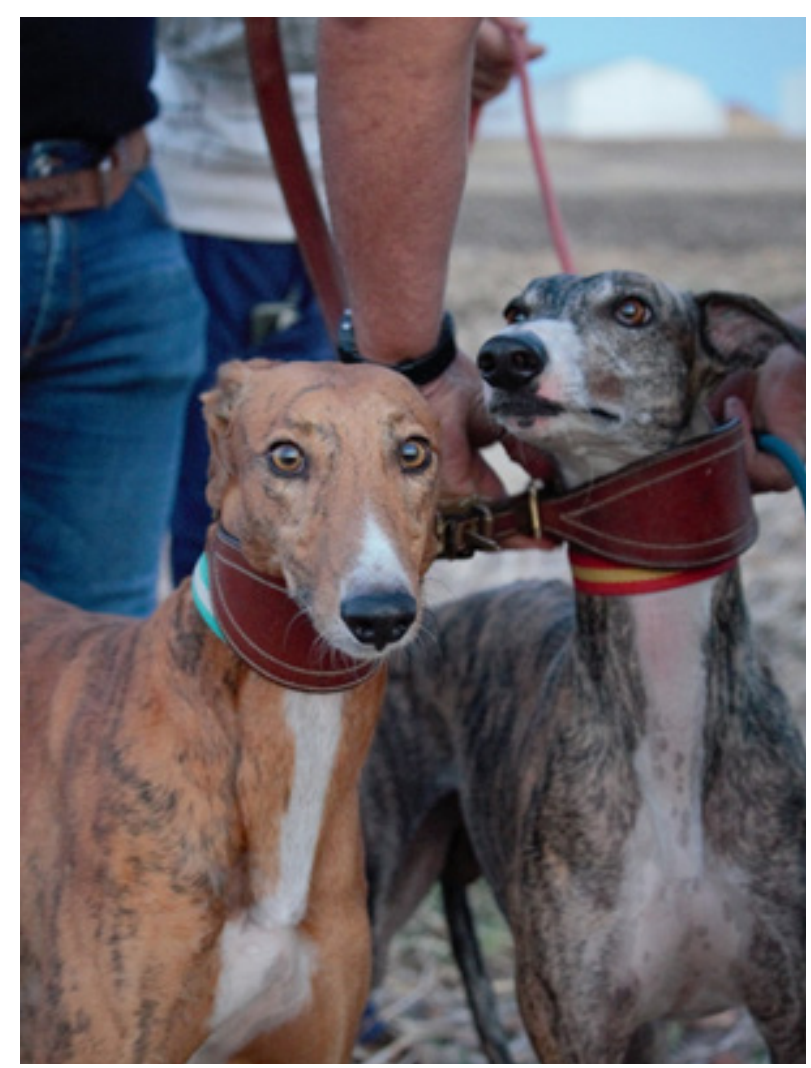

Imagen 2. Galgos atraillados.

Fuente: Helena P. Gamuz. de especies cazables, se realizaba como apoyo o aporte nutricional a los hogares, sobre todo en el mundo rural andaluz (Romero, 2010). Pero la mejora de las condiciones de vida de la población general, y de la población campesina en particular, dio lugar al cambio en la concepción de la caza como oficioactividad utilitaria hacia una vertiente más recreativa $y$, más adelante en el tiempo, deportiva y competitiva (véase López Ontiveros 1994; Cruzada, 2019).

En Andalucía, la caza de liebres con galgos queda regulada a través de la publicación de lo Orden General de

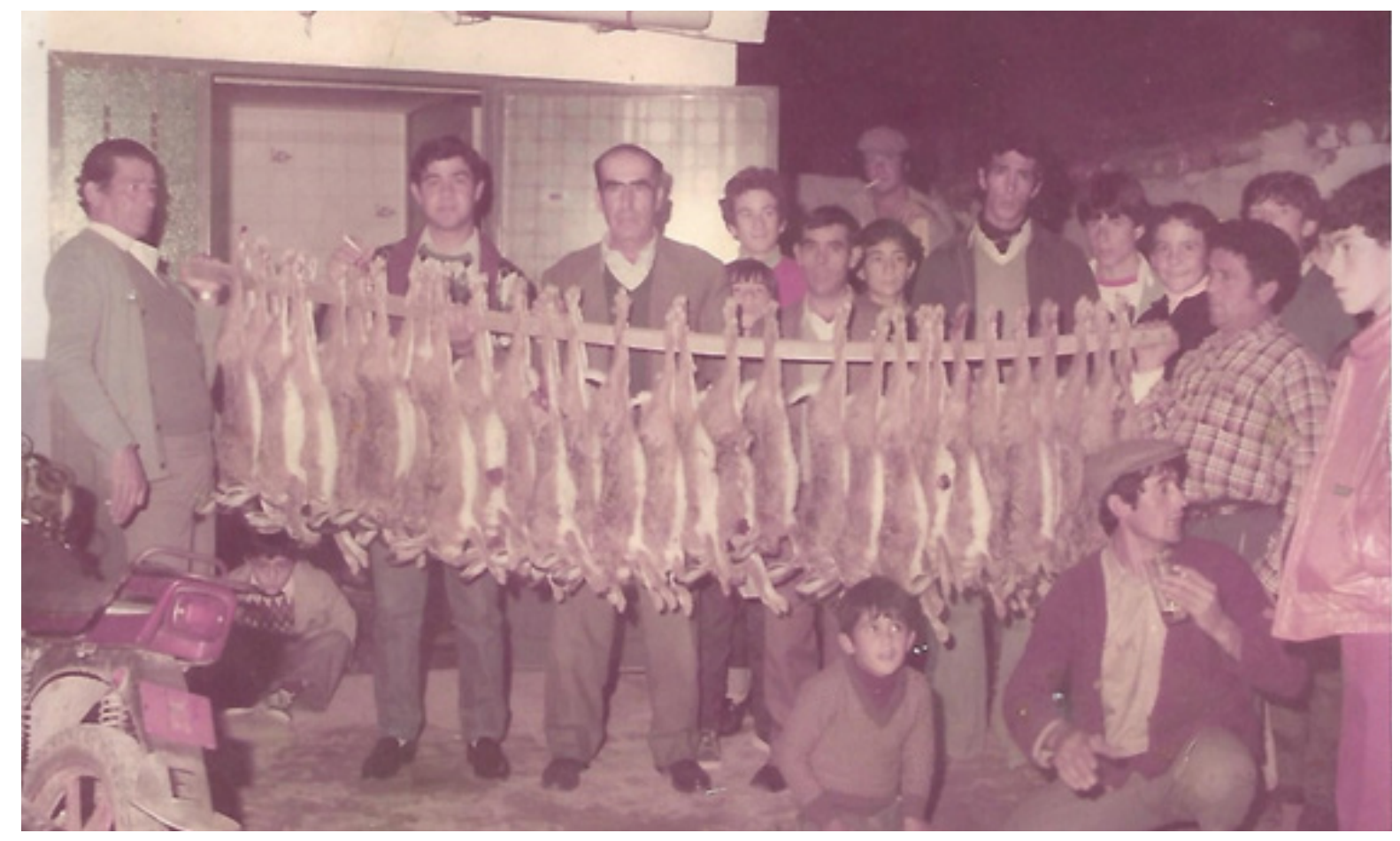

Imagen 3. Galgueros tras jornada de cacería en los años 80, en Olivares (Sevilla). Fuente: Amador Rodríguez. 
Vedas en el BOJA cada temporada cinegética, y con especificaciones que afectan a las diferentes modalidades de caza. El tiempo en que se abre la veda ocupa desde la segunda semana de octubre hasta finales de enero, coincidiendo con una baja actividad en el ciclo agrícola de las tierras de cultivo de las zonas de campiña. Esta concordia entre ambas actividades, el cultivo y la caza, ya se mantenía, por ejemplo, a finales del siglo XIX: "la caza con galgos a la carrera se hace desde que se concluye la vendimia hasta primero de marzo en que empieza la veda. Se colocan en ala los cazadores y se va recorriendo el terreno que se han propuesto hasta que salta la liebre" (VV.AA., 1858: 29).

Además de esta ordenanza que regula la apertura y cierre de la veda, existe una regulación interna, promovida desde las propias sociedades de caza y de galgueros, para la gestión de los cotos, ya que la legislación autonómica o nacional es exigua en estos asuntos. Tras la Ley nacional de caza de 1970, el Estado transfirió las competencias en materia cinegética a las Comunidades Autónomas en 1983 (Rengifo y Sánchez, 2016: 62). Es a partir de ese momento cuando cada región establecería una normativa específica para la actividad cinegética (Sánchez Gascón, 2007), pues la práctica se convierte en recreativo-deportiva más que en utilitaria. Desde entonces, Andalucía no ha sido prolija en el impulso de leyes de caza, y mucho menos en la regulación de la caza de liebres con galgos. La actividad cinegética en Andalucía queda ajustada, principalmente y en la actualidad, a dos textos legales: la Ley 8/2003 de Flora y Fauna Silvestres, y el Decreto 126/2017, de 25 de julio, por el que se aprueba el Reglamento de Ordenación de la Caza en Andalucía. Este último, en su Artículo 81, la define como una modalidad de caza menor en la que se utilizan galgos para perseguir y capturar liebres, "sin que se puedan usar armas de fuego, y que se puede practicar a pie o a caballo". Sin embargo, lo más certero y preciso que encontramos es en el Artículo 90 sobre protección de la caza, ya que se menciona en el segundo apartado que en la modalidad de caza de liebre con galgos "los perros deberán ir debidamente atraillados y solo podrán soltarse simultáneamente dos perros por liebre, permitiéndose soltar un tercer perro, siempre y cuando éste sea menor de dieciocho meses de edad, para su adiestramiento". 
Es por ello que las sociedades autogestionan y regulan las jornadas de caza de liebre con fin de salvaguardar y preservar a estas últimas, permitiendo su continuidad y reproducción. Normalmente se reservan dos días a la semana, y un cupo de liebres por collera de galgos. En la actualidad, dependiendo del coto, este cupo es de una o dos liebres. La problemática existente con la liebre silvestre, afectada por el virus de la mixomatosis y las modificaciones en el cultivo, tanto en el tipo como en la maquinaria empleada, los tiempos de recogida y la siega de la maleza que afectan a la reproducción y supervivencia de estas, ha supuesto la acentuación de las medidas de protección, formando parte sustancial de la gestión de las jornadas de cacería, así como de los terrenos para realizarlas.

Cada vez más se reservan cotos en los que no se caza para permitir su uso como zona de cría y cobijo. También la "caza sin muerte", con el uso de bozales para los galgos, se asocia a esta disminución y situación de vulnerabilidad de la liebre. Igualmente, se encuentran en auge los llamados "cercones", en los que se introducen liebres en estos terrenos vallados para su caza. Esta modalidad suscita rechazo entre los galgueros tradicionales, quienes defienden la autenticidad de la caza en campo abierto y se muestran reticentes a intervenir de esta manera en una práctica considerada en sí misma respetuosa con el medio y no interventora. Otra parte del colectivo, que no deja de ser heterogéneo, aboga por estas nuevas prácticas para la continuidad de la práctica, esta sí, más deportiva, para poder preparar a los galgos para su concurso en competiciones y campeonatos oficiales.

Con ello, se ha producido con el paso de los años una diferenciación entre los galgueros -a pesar de que ambas vertientes se solapan en la mayoría de los casos- entre aquellos enfocados a la competición, "galgueros deportistas", y aquellos "galgueros cazadores". Este proceso se asocia a la "democratización de la caza" (Sánchez Garrido, 2007: 216) en la que a partir de los años setenta se produjo un aumento del poder adquisitivo en la clase media de España, y que permitió el acceso a la caza como recreo de gran parte de la población. En el caso de la caza de liebres con galgos, más allá de la posibilidad de acceso a la práctica, ya que en términos de recursos para su ejecución no era, ni es, necesaria munición o armas refinadas, se produjo una creciente aspiración de los galgueros "de a pie" a participar en los campeonatos reglamentados que llevaban desde 1911 sucediéndose en los campos andaluces (Romero, 2014), y donde en primera instancia sólo participaban familias aristócratas. De ahí que hoy este cariz competitivo y deportivo haya ido tomando los campos y calando en el sentido de la caza de liebres con 
galgos, así como en la relación entre galgueros y galgos ${ }^{8}$.

\section{EL UNIVERSO GALGUERO ANDALUZ}

Andalucía reúne a nivel orográfico y de ecosistema unas características únicas que permiten la caza de liebre con galgos, ya que esta solo puede llevarse a cabo en grandes llanuras y campos de labor típicamente asociados al cultivo del cereal, del girasol, el algodón y las leguminosas, siendo estos terrenos donde prospera la liebre y donde se

8. La celebración en 1911 de la primera Edición de la "Copa de la Ina" en Jerez de la Frontera, supuso el debut en Andalucía de las carreras de galgos en competición, fuera de los canódromos urbanos, entre aristócratas y burgueses criadores de galgos, al mismo tiempo en que la caza con galgos seguía siendo una práctica generalizada entre la población rural andaluza campesina y jornalera. Durante el proyecto de investigación que sustenta la redacción de este artículo no hemos constatado, ni desde la Federación Andaluza de Galgos, ni entre las posiciones expresadas por nuestros informantes, la percepción de un conflicto interno en el colectivo por la simultaneidad de la doble orientación: a) recreativa (la caza de liebres en campo abierto) y b) deportiva (campeonatos oficiales de carreras de galgos tras las liebres). Tampoco se expresa esa doble finalidad de la actividad como conflictual en las publicaciones cinegéticas especializadas. No obstante, sí hemos recogido en nuestras entrevistas informaciones sobre ciertas prácticas mercantilistas que conlleva la dedicación preferente, aunque no exclusiva, a la participación en los campeonatos deportivos. El coste asumido por los propietarios de los galgos destinados a la competición incluye la alta tarifa de la monta de los campeones, la alimentación especial, la continua atención veterinaria, el entrenamiento, el abono de la tasa de inscripción en las pruebas, el pago de las carreras de liebres en terrenos vallados, los desplazamientos y los gastos para la protección frente al robo de galgos, entre otros intangibles. La capacidad para asumir esas obligaciones pecuniarias segmenta al colectivo de galgueros en dos partes asimétricas. Aunque no existen estadísticas sobre el porcentaje de galgueros dedicados a la caza recreativa y/o a las competiciones, las estimaciones más compartidas es que los galgueros jóvenes, a título individual o en grupo asociado, se sienten más atraídos por los campeonatos y si continúan practicando la caza con galgos lo hacen como parte de la preparación de sus perros para la competición. Esta inclinación por la participación en los campeonatos está desviando el sistema de valores de la relación humano-animal hacia la conversión del galgo en una mercancía que reproduce valor. Pero, ninguno de nuestros informantes reconoció la existencia de apuestas en los campeonatos y sí remarcaron que el premio nunca es en metálico, sino un trofeo para el propietario y, sobre todo, el enorme prestigio como criador y entrenador de un campeón nacional que puede generar futuras rentas para su dueño. 
producen las "grandes carreras" asociadas a la práctica. Además, los olivares, también característicos en el paisaje andaluz, forman parte del mismo ecosistema en tanto que son cobijo para la reproducción de la liebre, actuando como "perdederos", es decir, como lugares donde se refugia este animal para protegerse de los galgos, pero también de la depredación de otras especies como águilas y halcones. Este paisaje agroecológico de la Baja Andalucía, denominada por el colectivo de galgueros como la "Andalucía galguera", se caracteriza por ser una extensión de tierra deforestada, con llanuras y cerros poco pronunciados, una tierra rica, irrigada por los numerosos afluentes del Guadalquivir, desde la Sierra de Cazorla hasta el Parque Nacional de Doñana, convirtiendo en tan fértiles las zonas de campiña.

A pesar de que la liebre ibérica se encuentra en una amplia variedad de agroecosistemas, distribuyéndose desde el Mediterráneo hasta el Atlántico, y desde la Meseta Norte hasta la Costa Andaluza (Palacios y Mejide, 1979), existe una clara preferencia en ella por extensiones amplias y abiertas, con algún matorral y cercanas a los lugares de refugio como pueda ser viñedos, olivares y dehesas (Riqueni Barrios, 2012: 173). Estas claras preferencias por agroecosistemas específicos condicionan la aparición y proliferación de su caza con galgos, asociándose, en Andalucía, a los paisajes de campiña que acompañan la mayor parte del Valle del Guadalquivir (López Ontiveros, 2003):

"La zona de campiña por antonomasia, como son las campiñas de Sevilla, de Córdoba o Cádiz [...] son campiñas galgueras del conjunto del territorio de Andalucía [...] tierras buenísimas y ricas para el cultivo, llanitas, excepcionales para correr las liebres" (A.R.R., 66 años, político, Humilladero, Málaga).

Córdoba y Sevilla son las provincias más vinculadas a este paisaje, así como Cádiz, Jaén y Huelva, en menor medida. La caza de liebres con galgos en Andalucía se ha visto favorecida también por los usos históricos del suelo y su gestión, así como por las formas de vida que en ella se han dado y se dan. Los grandes terratenientes, con el monopolio de las tierras, favorecieron la aparición de latifundios y "agrovillas" (López Ontiveros, 2003), mientras que, por otro lado, la población jornalera, desposeída de tierra y empobrecida, se veía abocada a la captura y caza de especies como el conejo, la liebre o la perdiz a través de la instalación de trampas o la suelta de galgos durante las jornadas de trabajo, permitiendo así llenar la despensa en épocas de escasez (Palenzuela, 1996; Romero, 2010).

A través de los datos facilitados por el Instituto de Caza y Pesca Continental de Andalucía, se puede deducir que, del total de 6557 licencias expedidas para la caza sin arma de fuego en la región, unas 5958 se corresponderían con licencias para caza de liebres con galgos 
para el año $2020^{9}$. Además, estas licencias se corresponden con las provincias de Sevilla, Córdoba y Jaén, y en menor medida con Huelva, así como con Málaga y Cádiz, donde solo parte de su orografía favorece la práctica de esta modalidad cinegética. Estas zonas de campiña pueden entenderse como las "zonas de influencia galguera en Andalucía", pero, más ampliamente, como apuntaba Bonnemaison (2004: 56 y 130), supondrían un espacio que, por razones culturales, reviste a los ojos de ciertos pueblos una dimensión simbólica que los fortalece en su identidad, es decir, forman "una unidad de arraigo constitutiva de identidad" 10 . Como ya se ha apuntado en otros trabajos:

"La percepción del territorio y su significación real/material y real/simbólica no sigue un recorrido homologable ya que el significado que adopta el territorio para cada sociedad viene marcado por la evolución de los usos y aprovechamientos del espacio y por las formas de apropiación de éste a lo largo de su proceso histórico" (Palenzuela y Hernández, 1995: 123).

9. Existen en Andalucía 5 tipos de licencias de caza: Tipo A, que se corresponde con la práctica de caza con arma de fuego y otras modalidades. Tipo B, que se corresponderían con aquellas modalidades que no requieren armas de fuego. A la modalidad de "caza mayor, aves acuáticas y ojeos de perdiz" le corresponde el recargo tipo A para aquella modalidad con arma de fuego, y el tipo B para aquellas sin arma de fuego. El Tipo C2 se corresponde con la modalidad de caza de perdiz con reclamo, y el Tipo C1, para la cetrería. Por último, para la modalidad de "Medios Auxiliares de Caza" donde se incluyen las Rehalas, se expide la licencia C4. El margen de error de los datos que presentamos es reducido, ya que la única modalidad de caza menor con la que se compartiría ese recargo tipo B sería con la modalidad de caza con Arco, práctica bastante residual en la región. Además de esta, no contabilizamos, por imposibilidad de su trazabilidad, aquellos galgueros que también practiquen otras modalidades de caza con armas de fuego, y quienes estando en disposición de la licencia tipo A, se encuentran exentos de adquirir la licencia de caza sin arma de fuego tipo B, y que por tanto no estarían incorporados a este total.

10. A pesar de poder hablar de "pueblos galgueros" como referente de ciertos sectores en las sociedades locales, los cuales se identifican con la actividad, entendemos que no es extensible al conjunto de la localidad o región, ya que aquella parte ajena a la práctica no comparte ese sentimiento identitario. 


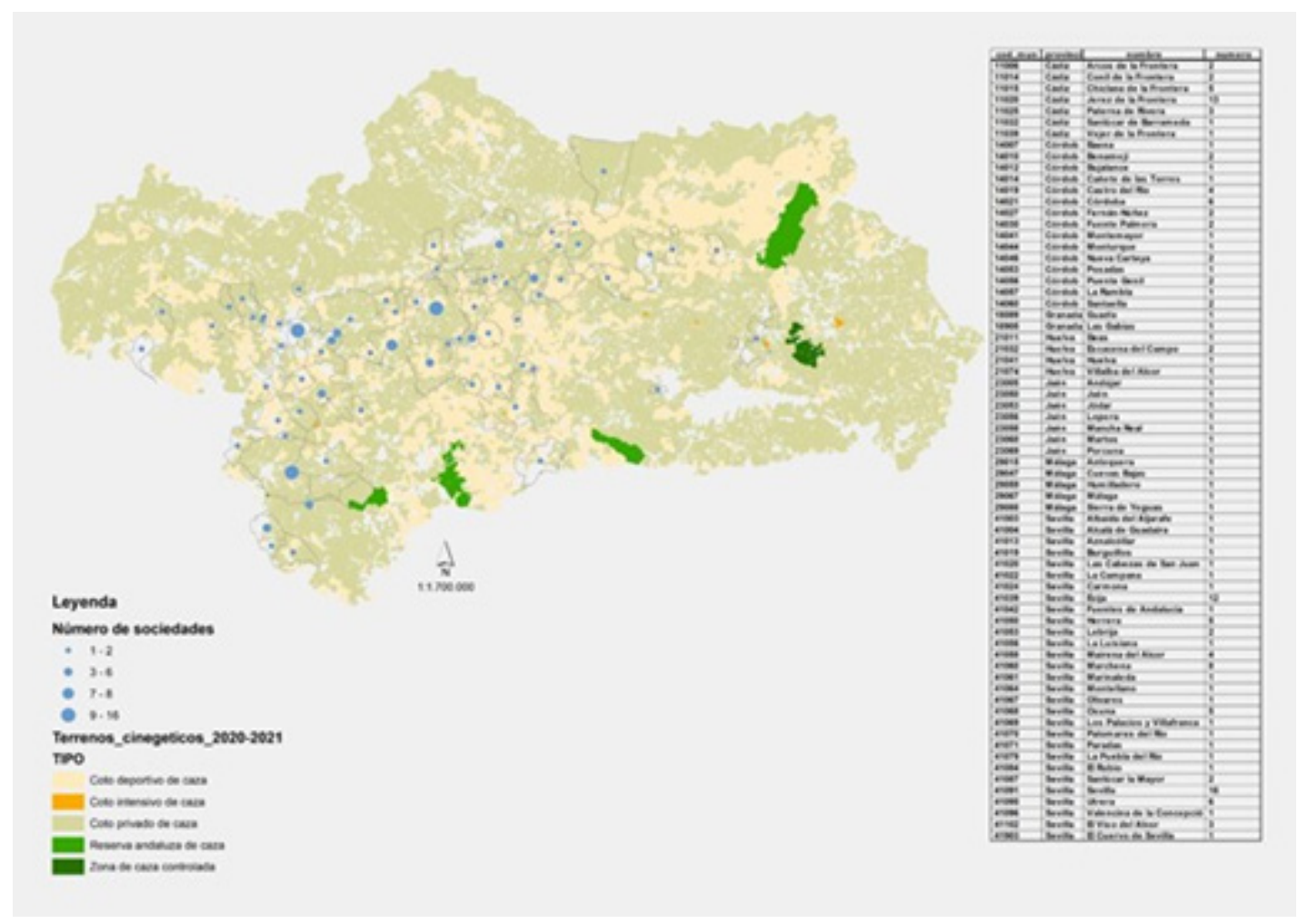

Figura 1. Densidad por provincias de clubes galgueros en Andalucía.

Fuente: Elaboración propia.

\section{VALORES ETNOLÓGICOS DE LA CAZA DE LIEBRE CON GALGOS EN ANDALUCÍA}

Andalucía se ha caracterizado por ser territorio de alta densidad y actividad cinegética, siendo rastreable esta práctica en los testimonios de obras como El Libro de la Montería de Alfonso XI (1887), o los tratados de caza que todavía se conservan desde el siglo XVIII (Calvo Pinto y Velarde, 1754; Fernández de Moratín, 1765; D.J.M.G.N.,1790). En estas obras se recogen conocimientos sobre el terreno, la flora y la fauna, los tiempos de caza, el "buen proceder" del cazador, el cuidado y atenciones tanto a los perros como al campo, y en términos generales, un vasto conocimiento construido en base a la vinculación al territorio y la relacionalidad entre especies. Sin embargo, en términos generales, la caza de liebres con galgos ha estado tratada de forma relativamente laxa a lo largo de la historia. Al realizar la revisión bibliográfica para la elaboración del informe técnico para el registro en el Atlas del Patrimonio Inmaterial de Andalucía, pudimos constatar que existe un repositorio de textos de contenido anecdótico y biográfico con relatos sobre las vivencias cinegéticas de autores y cuadrillas de galgueros, sin embargo, son escasos los estudios etnográficos, sociológicos o históricos sobre las mismas, en los que es fundamental conocer el valor cultural de este quehacer asociado -sobre todo- al mundo rural (Romero, 2010 y 2011; Seiru-lo Soares, 1978), o la naturaleza social de esta actividad cinegética, su reglamentación, ordenamiento y, en definitiva, sus valores etnológicos. 
En Andalucía, el movimiento asociativo galguero se hace patente a través del registro de los clubes inscritos en los Registros de Entidades Deportivas de Consejería de Educación y Deporte, donde aparecen un total de 159 clubs cuya mayor concentración se da en Córdoba, Sevilla y Cádiz, correspondiéndose, como venimos anunciando, con los socioecosistemas de campiña (véase el apartado 2). En esta densa red asociativa, se constituyen espacios concretos de sociabilidad y socialización, principalmente en sedes, locales y bares de encuentro, en un universo particular que emana tanto desde la compartición y transmisión de reglas, valores y saberes particulares de generación en generación, como de la relacionalidad especifica que dentro de ella se da. La caza de liebres con galgos, sin duda, se construye en base a esas reglas, valores y saberes compartidos que rigen el proceder de los galgueros como actores sociales dentro de un colectivo que los interioriza como parte de su identificación.

"Cuando uno está en el campo, no se concibe un día entre amigos corriendo liebres y después no pararnos a una cervecita, comidita, un picar y charlar de lo que nos gusta. Pero esto es no sólo en el mundo del galgo, es en cualquier cacería. Normalmente, la gente de campo cada una lleva sus cosillas, su talego, luego cuando se paran aquí está lo mío, venga, vale, se comparte todo" (M.A.V.T., 54 años, funcionario de prisiones, Puerto de Santa María, Cádiz).

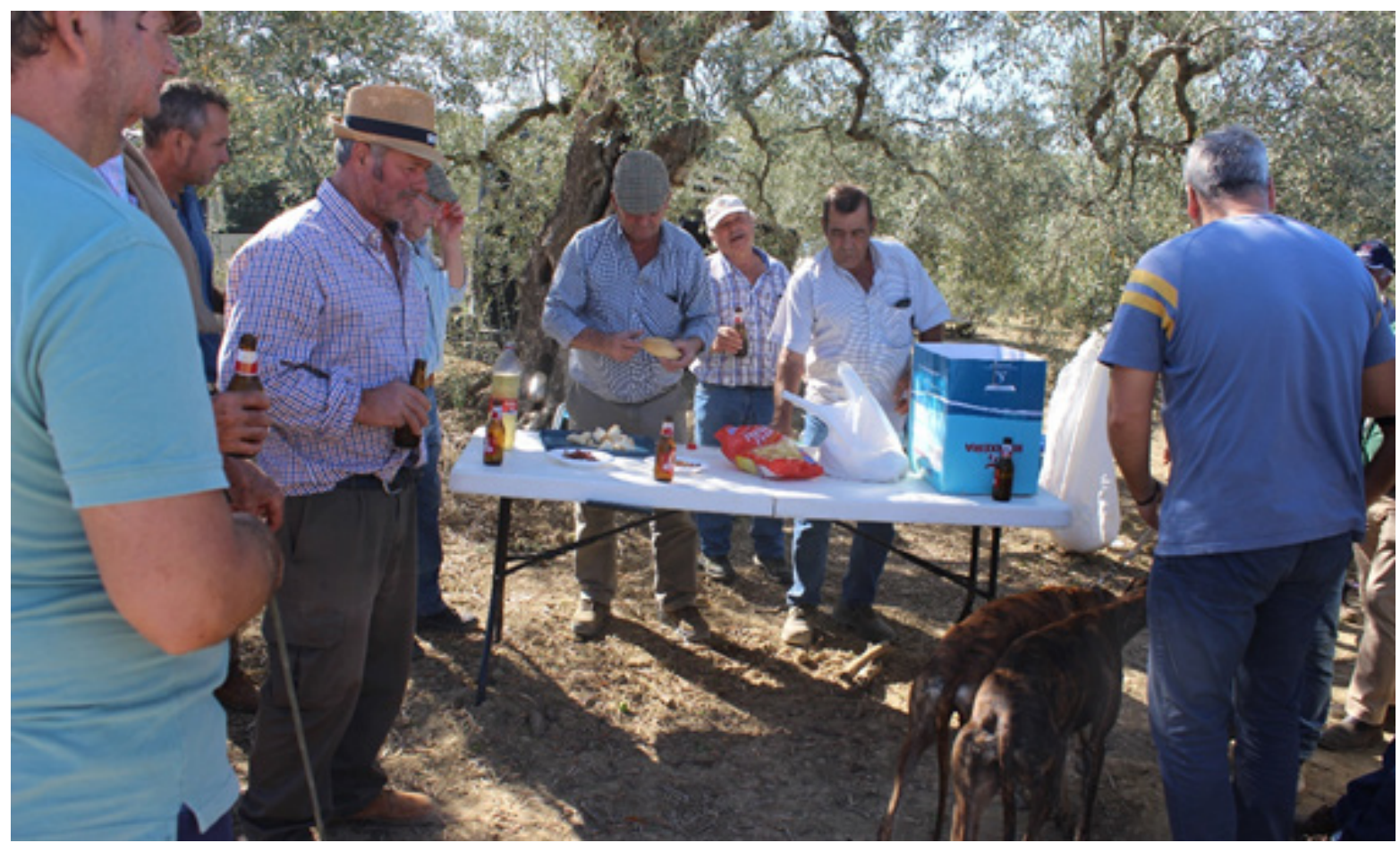

Imagen 4. Galgueros compartiendo sus viandas en una jornada de cacería.

Fuente: Santiago M. Cruzada 
En las trayectorias o historias de vida de los galgueros, en términos generales y casi sin exclusión, se constata el inicio en esta práctica en su infancia o adolescencia, con frecuencia de la mano de abuelos, padres, tíos o, a lo sumo, algún vecino que "era como de la familia". Esta afiliación constituye, además, "una particular forma de vincularse al territorio local, especialmente por hombres de la localidad que encuentran en la práctica una forma de relacionarse también entre ellos y mantener vínculos socio-afectivos e identitarios" (Gamuz, 2021: 75). Sin embargo, no podemos olvidar que la decisión de agruparse en una sociedad local de galgueros puede responder también a razones utilitaristas o de auto-identificación:

"Llegué aquí, de socia, en 2004. Y me decían: si a ti no te hace falta, tú ya vas con tu marido. Yo quiero ser socia, yo quiero pagar mi cuota de inscripción y cazar tranquila. Y desde entonces ya he estado cazando pues como un socio más" (M.R.C., 51 años, trabajadora del campo, Fuentes de Andalucía, Sevilla).

La frecuencia de relaciones cruzadas, tanto en el campo durante las cacerías como en la interacción social, crea lazos de amistad duraderos, educa para la aceptación de las decisiones colectivas y diluye, aunque no anula, las diferencias clasistas internas mediante la percepción de un ilusorio igualitarismo:

"Los galgueros ya tenemos una amistad, una práctica basada en la actividad. Yo tengo amigos del galgo que me han invitado a sus bodas, me han invitado a cumpleaños de los niños, a bautizos, a comuniones... amigos galgueros [...] y luego en los pueblos hay mucha amistad, cuando acaba la temporada hacemos una comida todos. Hay mucha relación con el tema del galgo" (F.M.C., 55 años, asesor fiscal, Escacena del Campo, Huelva).

"El galguero, en su gran mayoría ha sido un hombre humilde, más con idea de izquierda. En sus orígenes la práctica es humilde, de las entrañas del mundo rural. Ahí es donde nace, yo creo, el galgo. Pero también llegas a un campeonato de España, y ves a los Domecq y ahora ves a los gitanos, todos conviven" (J.L.C., 48 años, hostelero, Villanueva del Ariscal, Sevilla).

La auto-identificación como miembro del colectivo de galgueros cristaliza como resultado de la continuidad de las acciones de socialización y de la repetición de las prácticas, tanto dentro como al margen del tiempo concreto de las cacerías y, sobre todo, viene del aprendizaje empírico de las técnicas y saberes. Por lo tanto, la adquisición de esa identidad no está genéticamente adscrita (se afirma a menudo que "el galguero nace", o que "se lleva en la sangre"), sino que es el resultado de ese proceso social. Los autodefinidos como auténticos galgueros tienen claras las fronteras de su identidad ("se es o no se es galguero") y los marcadores que la definen: pasión por los galgos, afición a la 
caza de liebres, conocimiento del terreno ("saber leer el campo"), capacidad de esfuerzo, constancia, dedicación continua, independencia y, al mismo tiempo, cooperación y solidaridad.

Por su parte, en la relación mantenida con los galgos, se puede observar cómo este perro es reflejo de un proceso socio-genético selectivo dilatado en el tiempo y que ha configurado lo que hoy conocemos como "galgo español". Puede entenderse este como emblema de la "zootecnia" (Digard, 1990) ya que, más allá de ser rastreable su presencia en la historia occidental (véase Romero, 2010), la selección artificial del galgo se produjo y sigue produciéndose expresamente por los seres humanos para constituirse como los perros más veloces entre los de su especie, y desde sus orígenes su cometido fue la persecución y captura de liebres a la carrera, siendo esta última, la liebre, un elemento clave en la creación de la "raza". Puede apreciarse, en este caso particular, cómo los perros de caza, y los galgos específicamente, permiten al cazador el acceso a un mundo inaccesible para él que le permite de esta forma extender su campo de actuación (Kuhl, 2011).

Sin embargo, el galgo se encuentra situado en un estado de liminalidad constante, moviéndose en un estatus fluctuante entre "animalidad-salvaje" y lo excesivamente "humanizado-domesticado" (véase Dalla Bernardina, 2000). Comentan los galgueros y galgueras que los galgos deben mantener y responder a su "instinto" perseguidor, pero a la vez, también deben conocer los límites de esta "naturaleza", respondiendo y adecuándose a unos valores y normas cinegéticas específicas. A pesar de estas cuestiones, los lazos de unión entre galgueros y galgos se muestran frágiles y, en última instancia, supeditados a la utilidad-funcionalidad dentro del ámbito cinegético, sin tener por qué ser incompatibles con afectos, apego o respeto al perro durante su vida con el cazador/a. Es por ello que no se pueden obviar aquellas relaciones de poder específicas creadas entre humanos y canes, siendo los galgueros, a fin de cuentas, quienes determinan las alianzas, desencuentros, pertenencias y utilidad del perro para la caza. Lo que en otros trabajos se ha denominado "acoplamiento" entre perro-humano (Cruzada, 2019) determina la concepción del galgo como "bueno" o "malo", es decir, que si las aptitudes y actitudes del perro encajan en la idea de galgo que tienen los galgueros, y por tanto la idea del tipo de caza que se practica, se produce una "intensificación" del vínculo entre ambas partes pudiendo configurar, por ejemplo, linajes y memorias de parentesco multiespecie o un status y reconocimiento social extendido:

"Te puedo decir que un galgo le daba nombre a una persona. 'Fulanito el de la Paloma' quería decir que tenía un galgo que se llamaba Paloma y todo el mundo lo conocía por el galgo, es decir, un galgo bueno era capaz de darle nombre a la persona" (J.A.D., 76 años, empresario, Sevilla). 
"Los galgos pertenecen a la familia, porque quien los cría y quien los cuida, los mete en casa, lo quiera o no [...] Y después están los que tienen el [mismo linaje de] galgo desde sus ancestros, y está criando siempre su misma reata y sus mismas familias que creó su abuelo y su padre, no pierden su encaste, porque es la línea de sus antepasados" (J.L.C., 48 años, hostelero, Villanueva del Ariscal, Sevilla).

En cualquier caso, y como ocurre en otras modalidades de caza (Cruzada, 2019), se produce una subjetivación de los galgos, así como de las liebres, concibiéndose a ambas especies como los principales "agentes" de la actividad. Sin embargo, es innegable que la acción venatoria se maneja, construye y desarrolla exclusivamente por los cazadores, que gestionan las cacerías, los acotados, o los tiempos de caza, entre otras cuestiones. Se trata, entonces, de asumir que la práctica cinegética no podría desenvolverse sin una codependencia entre sus partes y, por lo demás, requiere de ciertos cuidados y supervisión específica por parte de los cazadores:

"Cuando se empezó a fundar el coto necesitamos pedir los permisos para cazar. Desde entonces nosotros los galgueros gestionamos la caza de liebres, y las mantenemos, miramos cuántas hay, cómo están de salud, si tienen comida, si no se la ponemos, y bebederos en verano. Los galgos están hechos para cazar las liebres, son un tipo de animal que se ha hecho para eso [...] si no hay cuidados al coto no hay liebres, y si no hay liebres no hay galgos" (J.P.B, 41 años, albañil, Olivares, Sevilla).

En ese sentido, la caza de liebres con galgos en Andalucía entraña, también, un conocimiento profundo -o experto- en torno a las múltiples dimensiones que afectan a esta práctica cinegética. Desde el punto de vista etnológico, es clave el conocimiento sobre los terrenos cinegéticos o cotos, sobre la climatología, pero de manera fundamental, el saber asociado a los animales que participan en la actividad, tanto sobre los galgos, como sobre la liebre. Es decir, los galgueros y galgueras son capaces de leer e interpretar, en clave biosemiótica, las señales encontradas en el campo. Estas formas de interpretación quedan ajustadas, mayoritariamente, a unos registros no simbólicos de conocimiento, que se vinculan de manera directa -tras largas y continuadas observaciones- a experiencias vividas entre humanos y animales (Ginzburg, 1989; Favareau, 2010). Como venimos apuntando, son el resultado de un dilatado proceso de enseñanza y aprendizaje transgeneracional y "más que humano". Por ejemplo, la elección del terreno sobre el que se caza viene demarcado por la aptitud de sus características orográficas para la carrera del galgo, el estado de las faenas de trabajo en el ciclo agrícola, pero también, además, por ser un espacio donde se presuponga que hay liebres: 
"Mi abuelo me enseñaba cómo está el terreno, por dónde se caza, o dónde se pone la liebre. Porque la liebre tiene querencias, como todos los animales, le gusta estar más en un sitio. Le gusta los 'regajitos', pero depende de la época' (F.M.C., 55 años, asesor fiscal, Escacena del Campo, Huelva).

"Lo primero es saber qué tierra es más propicia para la liebre, qué clase de terreno le gusta a la liebre más para encamar, y qué clase le gusta menos, eso para empezar" (M.R.C., 51 años, trabajadora del campo, Fuentes de Andalucía, Sevilla).

Además de los conocimientos específicos sobre el terreno, cazadores, perros y en algunos casos, caballos, deben disponerse de forma específica al "batir" el campo para poder identificar a la liebre en su "cama". Esta es resistente a las perturbaciones y una "experta del camuflaje", dicen los cazadores, por lo que los galgueros apuntan la necesidad de mantenerse a una distancia ni muy larga, ni muy corta unos de otros, que permita abarcar con la mirada una porción razonable de terreno, y caminar en silencio. Factores como el clima, la estacionalidad, o la temperatura, también marcan el proceder de esta caza, especialmente en lo que tiene que ver con el aire o el viento, el agua, el calor, el frío o los ciclos estacionales, que modifican los comportamientos y las "querencias" de las liebres. Por ejemplo, si las temperaturas son bajas, ha de buscarse a esta cerca de los arroyos, si está el terreno arado, ha de buscarse en cada grama o retama que se encuentre al paso:

"Hay que saber las querencias de la liebre, y nunca darle el aire a la liebre, siempre en contra del viento [...] Fundamental buscar referencia de si ha llovido, pues las pisadas frescas se notan de una vista, de ver las uñas clavadas de la liebre [...] La liebre tiene su sitio y su hábito, y cuando ves pisadas, la cosa -decimos- ya se está calentando" (A.R.R., 66 años, agricultor, Posadas, Córdoba).

Sin lugar a dudas, uno de los conocimientos más remarcables en el ámbito de la caza de liebres con galgos es el que se produce sobre las liebres. Los galgueros y galgueras conocen las pautas etológicas de este animal con precisión, y este conocimiento supone una herramienta metodológica que favorece a los cazadores asumir, representar y controlar las circunstancias particulares en las interacciones cinegéticas. Conocer el "mundo circundante" de las liebres, saber la "subjetividad de especie" que posee el animal (Uexküll [1934] 2016: 52) es importante para que se produzcan las carreras. Los galgueros, por tanto, tienen como tarea principal extraer los signos perceptuales de las liebres para poder reconstruir sus "formas" de vida.

"La hembra y el macho se diferencian en el campo por la cama. El macho escarba más y hace su cama a más profundidad, la liebre hembra, la cama es más somera, saca menos tierra" (A.R.R., 66 años, político, Humilladero, Málaga). 
"Las liebres de las águilas se esconden, se esconden porque las matan en campo abierto. Ellas bailan más, entonces, ahí, en los olivos, o bien, en verano, la defensa natural de ellas son los arroyos, donde está la maleza, y donde hay olivo intensivo y naranjo, y ellas se meten ahí para su defensa y no hay quien las vea" (A.R.R., 66 años, agricultor, Posadas, Córdoba).

Se produce así un pensar por/con el animal (Ortega y Gasset, 1962), y una adaptación por parte de los galgueros/as a las disposiciones sensoriales que les son atribuidas a los animales que se quieren cazar, lo que supone una compleja experiencia humana perceptiva (Zuppi, 2017). En ese sentido, podría asumirse que los mismos experimentan una doble perspectiva, la que los sitúa como cazadores y la que explora las respuestas y las consecuencias de sus acciones en las liebres (Cruzada, 2019). Sin esta doble perspectiva, sería muy difícil que los galgueros proyectaran sobre las liebres una capacidad para aprender de las acciones cinegéticas, o que desarrollen estrategias específicas, muy "inteligentes", para zafarse de sus depredadores:

"Cuando una liebre ve correr a los perros dos o tres veces, ella aprende en la forma de esquivarlos [...] Cuando ya la temporada está más avanzada, hay menos liebres, o la liebre se camufla más, porque la liebre a lo largo de la cacería también va aprendiendo de nosotros, de los cazadores y de los galgos" (A.T.P., 75 años, agricultor jubilado, Fuentes de Andalucía, Sevilla).

A pesar de todos los conocimientos específicos que los galgueros han de tener sobre el "mundo circundante" de las liebres, así como acerca de sus "patrones de conducta duraderos" (Baker, 1968), igualmente han de sumergirse dentro del mundo específico de los galgos, principalmente cuando se producen los lances de caza, donde los galgueros han de estar atentos a los gestos corporales que hacen los perros y a las señales específicas que realizan durante las carreras. Esto les permite saber qué galgo es más apto para qué circunstancia cinegética, o, por ejemplo, en qué tipo de terrenos se desenvuelve mejor un perro u otro, o qué variedad de galgo se ajusta más a sus ideales cinegéticos. Por lo demás, los galgueros intentan ponerse en el "pellejo de los perros", como ellos y ellas manifiestan, de modo que puedan adquirir conocimientos para seleccionar futuras camadas, para realizar entrecruzamientos, o para mejorar las características venatorias de los nuevos animales, de los galgos principiantes. Esta "empatía transespecie", ahora visible en la relación humano-canina, es, sin duda, unos de los alicientes de la práctica.

\section{EL CONFLICTO COMO ALICIENTE Y CATALIZADOR PATRIMONIAL}

Durante la última década, el colectivo de galgueras y galgueros andaluces ha recibido un sinfín de acusaciones en torno a sus prácticas, particularmente en lo que atañe a las relaciones y trato que mantienen con los galgos. El abandono de galgos, las prácticas 
cruentas, o la matanza sistemática de perros son algunos de los discursos que aparecen con recurrencia en diferentes medios de comunicación. Estas críticas que reciben los galgueros se basan, mayoritariamente, en las ideas de humanidad e igualdad de derechos con criaturas no humanas (Signer, 1975). Es en este plano donde cabe reflexionar sobre las relaciones humano-animales en el contexto de la caza de liebres con galgos, particularmente en su dimensión ética y moral, antes que ontológica. En términos generales, el enfrentamiento directo es a nivel discursivo, y aunque latente, diversos colectivos animalistas critican y criminalizan las actividades de los galgueros y galgueras como violentas, sádicas, brutales y basadas en el uso utilitario de los perros para satisfacción humana (Robinson y Watkinson, 2020). En el caso de los galgos se acentúan estos discursos, siendo este tipo de perro el "mártir" de los perros cazadores. La imagen que se proyecta del galgo es la de una criatura delgada, huidiza, con las orejas retraídas y la mirada vigilante, factores morfológicos determinantes en ese "desconsuelo" que emana ante su presencia en cualquier contexto en el que la figura del galgo aparece ${ }^{11}$.

Los galgueros y galgueras aseguran que no están al margen de estos discursos, y que son conscientes de ellos y de lo que suponen para su colectivo. Afirman igualmente que reciben estas noticias de manera directa, es decir, que las auto-personalizan, y las buscan, las intercambian y las interiorizan, comentando que, de manera general, se sienten criminalizados y estigmatizados. Sin embargo, no tiene sentido -como ellos mismos apuntan- negar la existencia de malas praxis, de violencias y de los maltratos que puedan darse en esta modalidad cinegética, mostrándose igualmente críticos con ellas:

"Yo el animalismolo entiendo, yo he publicado en mis redes sociales 'no al abandono de mascotas'. Yo cojo un perrito, qué bonito de chico, y luego lo abandonas. No comulgo con el cazador que esté a favor del abandono. No se puede maltratar a los animales, pero es que los animales también tienen su función. El que no sea ecologista no tiene sensibilidad en este sentido" (J.L.C., 48 años, hostelero, Villanueva del Ariscal, Sevilla).

Sin embargo, tampoco encuentran sentido a la ingente cantidad de discursos que esencializan y simplifican las relaciones humano-animales que ellos mismos mantienen, y que van mucho más allá de una visión utilitarista con los animales. Al respecto, afirman que se produce una suerte de homogeneización de la totalidad del colectivo que dista

11. Es fácil encontrar en Web noticias relacionadas con estos asuntos. Simplemente escribiendo en un motor de búsqueda las palabras "galgo", "caza" y "sufrimiento" aparecen miles de noticias que critican, denuncian y criminalizan las prácticas y usos cinegéticos con estos perros. Por su parte, la imagen del galgo como animal frágil, melindroso, asustadizo, ha sido un recurso en la historia del arte, lo que sin duda ha favorecido la idea de desprotección de este animal en el imaginario colectivo (Romero, 2010). 
de ser la realidad. Los lugares de tenencia de los perros, la alimentación, los cuidados diarios, las condiciones físicas de estos, y su vinculación emocional, son elementos clave para los galgueros y galgueras cuando hablan en términos generales de "qué es lo que necesita un galgo". Subrayan, por ejemplo, que una de las críticas más recurrentes que escuchan, leen o ven sobre sus prácticas es acerca de los malos cuidados que les dedican a los perros, especialmente en lo que respecta a los habitáculos o espacios donde suelen estar los galgos. Esas cuestiones, afirman, chocan frontalmente con sus prácticas:

"Yo los tengo en una perrera, intentamos tenerlos lo mejor posible. Tengo una nave, con las perreras para que no entre aire, compramos un trozo de tierra por detrás y hemos puesto un muro bastante alto, y ahí tienen arena, ahí juegan, corren, tendrán cincuenta metros cuadrados, están bastante bien. Y al lado de mi casa hemos hecho otra: ahí tienen su paridera, su bañera, eso es un hotel. Lo otro una casa, y esta nueva un hotel" (M.R.C., 51 años, trabajadora del campo, Fuentes de Andalucía, Sevilla).

"Yo no los tengo en búnkeres, pero hay mucha gente que le tiene preparado a los galgos mansiones de lujo, con todo lo que el galgo necesita" (F.P.P., 53 años, agricultor y ganadero, Manzanilla).

Con mucha dedicación y empeño, los galgueros y galgueras se esfuerzan por tener a sus galgos "como a una persona", dándoles, según comentan, lo mejor que pueden darles: desde búnkeres y perreras que suponen un gran esfuerzo económico para muchas/os de ellos -y construidos por los incesantes robos de galgos-, a una alimentación a base de los mejores piensos, suplementación, guisos que preparan ellas y ellos mismos, vendajes y protección en el campo para evitar torceduras o heridas, cuidados veterinarios, relaciones cotidianas:

"Nosotros basamos prácticamente la alimentación en el pienso, en carne de caballo y en carne de pollo, que les gusta mucho. Le hacemos macarrones, arroz, y también dos veces en semana les hacemos guiso [...] Es una dedicación tremenda la alimentación de los perros y esto mucha gente no lo ve o no quiere verlo" (F.M.C., 55 años, asesor fiscal, Escacena del Campo, Huelva).

"Vas a echarle de comer todos los días, y te quedas un buen rato ahí, una hora o dos viéndolos jugar y juegas con ellos, que es un roce continuo [...] La otra noche me dice mi hija: mamá, que hay un perro chillando, ¿bajo? Vamos, que si es de madrugada y hay un perro chillando, vamos a ver qué le pasa. La noche que hay parto, esa noche no se duerme. Eso es vivirlo, no sé. Para nosotros es que los galgos son parte de nuestra vida" (M.R.C., 51 años, trabajadora del campo, Fuentes de Andalucía). 
"Desde que nacen todo el tema de vacunación, desparasitación, y toda la alimentación que mejora las condiciones de salud se las doy. Y si le pasa algo al perro, al veterinario corriendo, y si se lastima, al veterinario" (J.M.C.H., 49 años, ganadero, Jerez de la Frontera, Cádiz).

Igualmente, comentan que ante la idea de "maltrato" sobre los animales se sienten impotentes de no poder mostrar sus esfuerzos en cuidar a los perros para que estos se encuentren bien, sin embargo, también entienden que ello incluye, además, algo crucial para el bienestar del animal, esto es, el movimiento de los galgos en el campo, y la posibilidad de correr libremente, a "toda su potencia" y con frecuencia:

"Ahora hay un montón de personas, chavalas y chavales nuevos, que los tienen como animal de compañía, y bueno, pero el galgo no quiere eso, el galgo es feliz en el campo. El galgo es para correr, para sacarlo al campo, no es para ponerse en un sofá muy limpito. El galgo como es feliz, es en el campo. En las casas se les ponen las uñas así de largas de no gastarse" (R.B.P. 60 años, marmolista, Olivares, Sevilla).

En ese sentido, los galgueros y galgueras nos transmiten que las críticas sobre su colectivo se han convertido en un instrumento de vigilancia externa sobre sus prácticas, y suponen un mecanismo que encierra una especie de narrativa colonialista moderna acerca de lo que se debe y se puede hacer con los animales, que está siendo asumida por una parte de la sociedad sin cuestionarse desde dónde se producen los discursos y de qué manera se difunden. Pero si hay algo que verdaderamente preocupa al colectivo de galgueros es el robo y abandono de los galgos. Aseguran que la mayoría de animales que aparecen abandonados o muertos son fruto del robo previo por gente sin escrúpulos que pretenden hacer con ellos negocios turbios, a los cuales, sin duda, no los consideran como parte de su colectivo:

"Al chaval, de la perrera, Manolo, a ese chaval le han robado trece veces. Ese chaval se ha hecho una perrera ahora, que está preciosa, la perrera en sí es un búnker, bien hecho [...] Normalmente van a robarlos, y si no es el mismo día, al siguiente los prueban, y los que no valen los sueltan por ahí, los tiran a un pozo o vete tú a saber. Los chips se los quitan. Yo le regalé dos perras a un amigo de Osuna. Y las dos se las robaron. Y había puesto la denuncia y le llama de la Guardia Civil que tenían a la perra en Cañadas (Madrid)" (P.C.V., 53 años, trabajador del campo, El Coronil, Sevilla).

“Teníamos un gran perro y nos lo robaron, le cogen la pista al perro, ya saben dónde estaba, de dónde viene, y ahí es donde empieza la mala fama que tenemos 
los galgueros. Vienen, te roban lo mejor que tienes, hacen apuestas ilegales, gente que no ha cuidado un galgo en su vida, y ahora el que no vale pues te lo tiran a la calle" (A.P.V., 27 años, agricultor, Manzanilla, Huelva).

Sin embargo, no es menos cierto que los fuertes lazos de unión que un galguero/a puede tener con su animal quedan supeditados a la funcionalidad de este en el ámbito cinegético. Pero esto, como nos dicen, no es incompatible con los buenos cuidados y el respeto al animal:

"Si no podemos tenerlos, a la protectora, que es porque le busquen un sitio para que ellos estén bien, procurando que los animales vayan a estar bien. Si no podemos, los llevamos a un sitio que lógicamente estén bien cuidados. Luego te mandan los videos que los tienen bien, son personas que lo tienen en sus pisos o casas. Y esto no sé por qué está mal mirado, porque se entiende que 'lo hemos tirado' o no nos sirven, o lo que sea, pero eso no quiere decir que nosotros no queramos esos perros o que le deseemos algo malo" (J.M.C.H., 49 años, ganadero, Jerez de la Frontera, Cádiz).

Aunque galgueros y galgueras experimentan todas estas cuestiones con frustración porque entienden que no se le da voz para poder contradecir ciertos argumentos que van en su contra, tienen al mismo tiempo la suficiente sensibilidad como para denunciar las prácticas que no creen adecuadas y que no se comprenden dentro de su universo ético y moral. El contenido del mismo, creen también, no puede ser monopolizado desde afuera, alienado de alguna manera en discursos que no tengan en cuenta los procesos más amplios de las relaciones que mantienen con sus perros y, por lo demás, afirman que son "precisamente los más interesados en luchar contra los malos tratos y la crueldad hacia los animales que amamos, y estamos siempre dispuestos a hacer campañas con asociaciones y poderes públicos para erradicarlo" (Romero, 2011:21).

Sucede así que esta presión manifiesta que experimenta el colectivo, la situación de vulnerabilidad y conflictividad que entienden que existe, se ha convertido en un aliciente y catalizador para la activación de procesos de protección patrimonial sobre sus prácticas. De este modo, el propio colectivo ha iniciado su estrategia para el reconocimiento social de sus prácticas, sus valores y sus formas de vida, lo que implica -bajo su prisma- una estrecha adscripción al territorio, a los animales y a un legado histórico. Esa dignidad y valorización ansiada por el colectivo de galgueros cristaliza una negociación o pugna en la construcción social del patrimonio, de donde deriva irremediablemente un juego de fuerzas, de conflictos y alianzas entre los grupos sociales, que con carácter eminentemente político reclaman la legitimación -social o incluso legislativa- de sus modos de vida. Como apunta Quintero (2009: 359), "el carácter procesual del patrimonio nos permite 
observar cómo determinados agentes van modelando sus posiciones, interactuando con otros y construyendo, en tensión y/o en alianza, los significados y usos asignados a los bienes".

El colectivo de galgueras y galgueros andaluces persigue que la caza de liebres con galgos deje de ser considerada, desde el grueso y la mayoría social, como una actividad "indigna", y de alguna manera se produzca una alineación entre las diferentes cosmovisiones que se dan dentro de este marco territorial andaluz. La idea de "patrimonio cultural" emerge para ellos y ellas como reflexiva, como una oportunidad de cambiar la conflictividad, y manifiestan que, efectivamente, necesitan de mecanismos institucionales que reconozcan una serie de valores que se dan dentro de la práctica:

"Obviamente, la deuda pendiente que tenemos ahora los galgueros y galgueras andaluces es conseguir que la sociedad no nos mire como a criminales, y esto se consigue empezando porque las propias administraciones públicas digan que no somos eso, que hay más cosas que eso [...] Nosotros luchamos por el reconocimiento patrimonial en ese sentido" (R.A.F., 53 años, miembro de la FAG, Sevilla).

Los galgueros y galgueras, aseguran, encuentran amenazada su práctica, y la continuidad de la misma en el tiempo. Esta presión e incertidumbre sobre la continuidad de una forma de vida que se entiende identitaria y definitoria de su "razón de ser", actúa como resorte para la movilización. El problema, no obstante, radica para ellos y ellas en que el "sujeto" de esta valoración adquiere carácter político, sobre todo cuando "se politiza tal o cual cuestión sobre los galgos en particular, pero sobre la caza en general" (A.R.R., 66 años, político, Humilladero, Málaga). Efectivamente, los procesos de patrimonialización implican "de manera ineludible procesos de autodefinición y heterodefinición colectiva, poniéndose en marcha relaciones de poder que legitiman -o no- el punto de vista propio, sobre qué representa a quiénes" (Cruces, 1998: 77). El carácter etnológico de estas prácticas cinegéticas, como elementos patrimoniales o "patrimonializables", tienen sin duda una naturaleza distinta a aquellos elementos que se enmarcan en el concepto tradicional de patrimonio como "histórico artístico", "inmueble" o "conjunto de bienes", por lo que entonces se vería dificultada su gestión, así como su reconocimiento:

"No son singulares, ni escasos, ni son importantes por sus valores artísticos, sino por sus significados socioculturales; aunque se apoyen en la tradición, son bienes vivos, y por lo tanto se transforman y usan cotidianamente. Además de sus propias características como patrimonio vivo, de la deuda histórica que tiene la sociedad y la tutela patrimonial en la valorización de este patrimonio, y de 
las dificultades para gestionar lo inmaterial y la identidad, existen otras causas que afectan directamente a este patrimonio vivo: los procesos de globalización y la aceleración de las transformaciones sociales actuales, comportan riesgos de deterioro, desaparición y destrucción de los valores inmateriales del patrimonio cultural y sobre todo del patrimonio etnológico" (Carrera Díaz y Delgado Méndez, 2011: 111).

Con estas cuestiones de fondo, el colectivo conoce las posibilidades que albergan el reconocimiento y respaldo de su práctica como herencia cultural, lo que entrañaría una serie de valores asociados a ciertos usos, representaciones, conocimientos y técnicas que los definen como colectivo y a través de las cuales se identifican. Sin embargo, y en cualquier caso, quizás no se hubieran visto en la necesidad de activar procesos de patrimonialización, como nos aseguran, si no sintieran que las mismas se encuentran en peligro, si no hubiese un conflicto en torno y sobre sus formas de vida. Sucede que la diferencia de prácticas y modos de relacionarse entre especies, y los mundos que de estas relaciones emergen, generan "choques" entre diferentes cosmovisiones, alimentando conflictos y enfrentamientos entre colectivos, desencuentros entre grupos y comunidades que, aun compartiendo espacio, no comparten el mismo modo de ser, estar y vivir en un territorio (Gómez Pellón, 2017: 151).

\section{APROXIMACIÓN A LOS PROBLEMAS DEL PATRIMONIO INMATERIAL CON ANIMALES}

Como ya se apuntaba en el apartado anterior, la noción de patrimonio cultural inmaterial se constituye como aquellos "usos, representaciones, expresiones, conocimientos y técnicas -junto con los instrumentos, objetos, artefactos y espacios culturales que les son inherentes- que las comunidades, los grupos y en algunos casos los individuos reconozcan como parte integrante de su patrimonio cultural" (UNESCO, 2003: Art 2.1.). A pesar de los cambios acontecidos desde que esta noción de patrimonio inmaterial se pusiera sobre la mesa -siendo uno de los más relevantes el papel fundamental que los grupos sociales ejercen de forma proactiva para el registro y reconocimiento de formas de vida con alto valor etnológico e identitario-, la misma no queda exenta de caer en manos de intereses político-económicos bajo "un uso neoliberal de la cultura como recurso" (Carrera, 2017: 7) que, junto a otros factores, acaba por producir un vaciamiento y "folklorización" de las expresiones culturales de los pueblos.

Además, emergen en nuestros días otros nuevos usos de las nociones patrimoniales vinculados directamente a las lógicas y discursos de un mundo hiperconectado y global, lo que sucede con frecuencia cuando se trata de debatir sobre la utilización de los animales en/por las sociedades humanas. Como afirma Gómez Pellón (2017: 151) “[se ha generado] 
la conciencia de la defensa de la naturaleza en general, y la de los animales en particular, hasta el extremo de que su protección se ha convertido generalizadamente en norma". En el contexto de la caza de liebres con galgos en campo abierto, su patrimonialización produce un choque con cierta dialéctica contemporánea que se fundamenta en las nociones de una animalidad próxima o solapada con la humanidad. Es por ello que categorizar esta actividad cultural como elemento a patrimonializar, sea después o no, efectivamente vinculante su conceptualización como patrimonio que se soporta bajo un marco jurídico determinado, supone una acción ética muy concreta que se posiciona en el universo moral de ciertos actores sociales y no de otros. Aparece entonces la idea de "conflicto patrimonial" en el sentido de la contraposición de procesos de protección sobre un elemento cultural, ya sean de un modo u otro, que chocan con fuerza en sus disputas y reclamaciones. Como señala Quintero (2009: 362), "la patrimonialización como un proceso dinámico [...] donde diferentes grupos 'negocian' -es decir, se enfrentan, coinciden, disputan o se alían- proponiendo unas definiciones, significados y usos de ciertos elementos".

Si bien es cierto que detrás de cada elemento patrimonializado existe un proceso de activación y articulación que lo eleva a la categoría de colectivo, no lo es menos que cada caso no está exento de negociaciones, conflictos, contradicciones, disputas, intereses antagónicos, relaciones de poder, asimetrías y tensiones (véase Sánchez-Carretero, 2017). En el caso de la caza de liebres con galgos en particular, pero más ampliamente en las actividades culturales en las que se utilizan animales en general, estas cuestiones son palpables. A ese respecto, Gómez Pellón (2017) entiende que aquellos valores "tradicionales" que se sustentan tras las actividades culturales con animales, no pueden por menos que chocar frontalmente con los valores de una sociedad posmaterialista y posindustrial que entiende a los animales no porque estos puedan ser apropiados, explotados o utilizados, sino que son valiosos en el sentido de que sus vidas son parte de una naturaleza admirable en las que no tienen cabida el maltrato, el sufrimiento o la crueldad hacia aquellos animales que se aman y que se entiende que "sienten". Además, añade, la mayoría de las prácticas históricas -al menos en nuestro país- en las que son utilizados los animales, se asocian a un dominio masculino que resultan inaceptable en una sociedad que cada vez más se construye asociada a los valores en igualdad de género.

Sin embargo, los valores de la tradición no pueden ser comprendidos como algo estanco e inalterado, ya que, formando parte del mismo tiempo y espacio, también en ellos permean las ideas de respeto a la naturaleza y a los animales, o acerca de la sostenibilidad ambiental, y no por ello entran en contradicción, como vimos, con las prácticas concretas. El conflicto es aquí, por tanto, además de ético y moral, ontológico, y se establece a través de la construcción de la noción de "naturaleza", de "animalidad" y en relación a 
dicotomías históricas que tienen que ver con lo "salvaje" y lo "civilizado". Efectivamente, en las nociones y dimensiones hegemónicas de los procesos patrimoniales suele pasar desapercibido la naturaleza conflictiva del patrimonio (Santamarina y Del Mármol, 2020), y los aspectos políticos, los económicos y las concepciones particulares acerca de cómo se entiende la realidad, además de las disposiciones y estrategias de cada quien, que se encuentran entrelazados. El tratamiento patrimonial de actividades culturales en donde los animales son partícipes de unas acciones humanas, por tanto, se sitúa en una perspectiva crítica que abre su análisis al carácter conflictivo del mismo (Smith, 2006; Harrison, 2013), de modo que en muchos casos ya no supone una disputa por patrimonializar la tradición, sino más bien una disputa por proteger ciertas ontologías que son el dispositivo fundamental para definir realidades concretas.

La etnografía se sitúa como una herramienta específica a través de la cual podemos repensar cómo en la caza de liebres con galgos en campo abierto, los galgueros y galgueras establecen relaciones tanto humano-animales como humano-ambientales profundas que configuran la noción de naturaleza no como una esfera separada, sino desde un sistema interconectado entre seres que configura la emergencia de un mundo multiespecífico. De esta vinculación "socionatural" surge una identidad social situada, y que como en otros estudios sobre modalidades de caza diferentes, trata de pensar y actuar en la naturaleza no como una esfera separada del ser, sino que la misma constituye su experiencia e identidad en el territorio, encarnando una posición que no reproduce un "naturalismo" ingenuo como modelo dominante en las sociedades occidentales desde la Modernidad, caracterizado por la alteridad y discontinuidad sociedad-naturaleza (Cruzada, 2017; Florido del Corral y Palenzuela, 2017).

Esta percepción no dual, que rebasa en cierta manera las conceptualizaciones de ese "naturalismo occidental" (Descola, 2012), supone entender las actividades humanas como insertas en tramas ecológico-culturales más amplias, donde la muerte de los animales también tiene sentido. Comentaba un informante que

"La muerte ha pasado a ser algo feo, cada vez somos más urbanos y menos rurales, cada vez creemos que la leche la echa la cinta transportadora, y que la carne la fabrican los grandes centros comerciales. No hablamos de parir, no hablamos de follar, no hablamos de comer, no hablamos de matar" (A.R.R., 66 años, político, Humilladero).

Efectivamente, podría entenderse que los deseos por querer patrimonializar actividades culturales en las que los animales se encuentran insertos supone, en la actualidad, una forma de instrumento de oposición en términos de su potencial contra-hegemónico a los sentimientos y percepciones sociales generalizadas (Hernández-Ramírez, 2007; Collins, 
2008). No obstante, no se elude la posibilidad de tender puentes al entendimiento entre los modelos de construcción y conceptualización de lo natural y de lo animal. Esta, creemos, no debiera darse de manera homogénea y estática, sino respondiendo a las consideraciones que cada grupo social posee acerca de los mismos. Las reflexiones y debates teóricos, y ético-políticos, o morales u ontológicos, deben por ello incluir las perspectivas culturales involucradas (Blaser, 2009), sobre todo cuando abordamos conceptualizaciones, valores y presupuestos ideáticos que giran en torno a prácticas culturales de las que otros seres no humanos son partícipes.

\section{CONCLUSIONES}

En la introducción quedaron expuestas las dos partes que componen la estructura de este artículo. Ambas secciones, tanto la etnográfica/descriptiva como la relacional/conflictual están imbuidas por la perspectiva antropológica que prioriza un enfoque cualitativo de la realidad social, sin menoscabo de la aproximación cuantitativa, y por el análisis del conflicto y la negociación entre los discursos ontológicos del colectivo galguero y los argumentos éticos y morales que cada vez más configuran el imaginario de una amplia parte de la sociedad, y dentro de la cual, los colectivos anti-especistas pueden ser los de mayor visibilidad mediática.

Hemos pretendido contribuir a la identificación y puesta en valor -en el marco de la patrimonialización- del conjunto de acciones, normas y saberes que encierra la práctica de la caza de liebre con galgos en Andalucía, y a través de la aproximación etnográfica pudimos verificar cómo ese bien es reconocido y apropiado por una parte del pueblo andaluz. Ante la escasez de textos que abordan este tema en su dimensión socioantropológica, entendemos el carácter pionero de este trabajo en la descripción etnográfica y en la identificación de los valores que encierra esta actividad tan arraigada en el medio rural andaluz, pero también sus limitaciones y la necesidad de revisión y ampliación de muchos de los puntos en los que no hemos podido ahondar. Más allá de este estudio y reconocimiento, nos hemos sumado al debate teórico y político sobre los procesos de patrimonialización como construcción social, y por tanto bajo los cuales entendemos que se hayan pugnas, negociaciones, tensiones y alianzas para la construcción de los significados y usos de los bien patrimoniales (Quintero, 2009).

La preocupación creciente de los galgueros por la continuidad de su propia existencia como titulares de un patrimonio inmaterial queda explicitada en los discursos de nuestros informantes y está en la base de la iniciativa de patrimonialización por parte de la Federación Andaluza de Galgos. Es relevante la aproximación a estos procesos y su cada vez mayor carácter conflictivo, especialmente cuando tratamos prácticas que implican relaciones entre humanos y animales. El choque entre las perspectivas que 
encarnan este conflicto, latente y de intensidad creciente, no aplica en exclusividad a la caza de liebres con galgo a pesar de ser este nuestro foco de estudio, sino cada vez a una más amplia gama de prácticas que impliquen animales, desde la caza, a los circos, el consumo de carne, los zoológicos, la ganadería, el uso de animales de tiro, etc. Por ello consideramos relevante la aproximación antropológica a muchas de ellas, y desde esta perspectiva poder entenderlas en mayor amplitud y sensibilidad. Las prácticas como la caza de liebres con galgos entrañan una ontología que, aunque atravesada por el régimen de "globalidad" en que vivimos, y absorbiendo conceptos como conservación, ecologismo, protección de la vida, o contraposición al maltrato animal, complejiza la comprensión de la misma.

La caza de liebres con galgos configura un mundo de entendimiento basado en una semiótica "más que humana" que, junto a las construcciones socio-culturales compartidas por los cazadores, modelan unas relaciones humano-animales muy específicas (Gamuz, 2021). La homogeneización de opinión publica a través de visiones monistas y moralistas de prácticas como las que aquí presentamos, pueden producir la pérdida de conocimientos expertos, mayoritariamente asociados al mundo rural andaluz, pero también alimentan y hacen extensibles barreras socioculturales, ontológicas y políticas entre lo rural y lo urbano, el conocimiento científico y el conocimiento local, y, a fin de cuentas, refuerza enfrentamientos frontales y pocos consensos. El mensaje estigmatizador, que homogeniza al colectivo de galgueros y galgueras, se integra, como apunta Gómez Pellón (2017), en el carácter conflictivo del tratamiento patrimonial de cualquier tipo de actividades culturales con animales. El epítome de esta problemática sería el caso de la declaración de la tauromaquia como Patrimonio Cultural Inmaterial (Ley 18/2013), lo que supone la patrimonialización de una tradición que es rechazada, no solo por los colectivos antitaurinos, sino por la propia UNESCO.

No obstante, queda abierta la posibilidad de un espacio convivencial entre los modelos de construcción y conceptualización de lo natural y de lo animal. Un "puente" que no debe construirse desde posiciones estáticas y homogéneas sino teniendo en cuenta las consideraciones que cada grupo social tiene de la naturaleza, no como una esfera separada e independiente de los seres humanos, sino como un sistema interconectado entre seres de un mundo multiespecífico. En definitiva, esta posibilidad consensual supone entender las actividades humanas como insertas en tramas ecológico-culturales más amplias, donde incluso la muerte de las liebres por los galgos también tiene sentido. Si el patrimonio es realmente un diálogo de saberes, resultado de un proceso y de una construcción social, el proceso de patrimonialización exigirá un ejercicio de resignificación y reorganización. Por ello, los procesos de patrimonialización constituyen un escenario privilegiado para observar el conflicto y aplicar un paradigma más democrático y participativo en la toma de decisiones. 


\section{REFERENCIAS BIBLIOGRÁFICAS}

Arriano, Flavio [s. II a. c.] (1965) Cynegeticus. Traducido por Beatriz Seral Aranda con título Tratado de la caza. Madrid: Colección el Mirlo Blanco.

Baker, Roger G. (1968) Ecological Psychology: Concepts and Methods for Studying the Environment of Human Behavior. Stanford, California: Stanford University Press

Blaser, Mario (2009) "The Threat of the Yrmo: The Political Ontology of a Sustainable Hunting Program”. American Anthropologist, 111(1), pp. 10-20.

Bonnemaison, Joël ([1981] 2004) “Voyage Autour du Territoire”, L'Espace Géographique, 4: 249-262. La Géographie Culturelle, Éditions du C.T.H.S., París.

Bulliet, Richard W. (2005) Hunters, Herders, and Hamburguers: The Past and Future of Human-Animal Relationships. New York: Columbia University Press.

Calvo Pinto y Velarde, Agustín (1754) Silva venatoria: modo de cazar todo género de aves y animales, su naturaleza, virtudes, y noticias de los temporales. Madrid: Imprenta de los Herederos de Don Agustín de Gordejuela.

Carrera Díaz, Gema, y Delgado Méndez, Aniceto (2011) "La antropologización del patrimonio y la patrimonialización de la cultura. Documentar el patrimonio etnológico en el IAPH". Revista Andaluza de Antropología, 2: 108-127.

Collins, John (2008) "But What if I Should Need to Defecate in Your Neighbourhood, Madame: Empire, Redemption, and the 'Tradition of the Oppressed' in a Brazilian World Heritage Site". Cultural Anthropology, 23(2): 279-328.

Cruces, Francisco (1998) “Problemas en torno a la restitución del patrimonio. Una visión desde la antropología”. Alteridades, 8(16): 75-84.

Cruzada, Santiago M. (2017) "El naturalismo accidental: críticas a un modelo teorético de legitimación socioecológica”. Arbor, 193(785): e406.

- - (2019) "Encuentros de vida y muerte. Antropología Transespecie y mundos ampliados entre cazadores y animales en el suroeste extremeño." Tesis Doctoral. Universidad Pablo de Olavide. Sevilla.

Dahles, Heidi (1993) "Game Killing and Killing Games: An Anthropologist Looking at Hunting in a Modern Society”, Society and Animals, 1: 169-189.

Dalla Bernardina, Sergio (2000) "Una persona no completamente como las demás. El animal y su estatuto". Gazeta de Antropología, 16: a9. 
Decreto 126/2017, de 25 de julio, por el que se aprueba el Reglamento de Ordenación de la Caza en Andalucía. Disponible en: https://www.juntadeandalucia.es/boja/2017/149/5.

Delibes, Miguel (1989) "La caza con galgos". La Vanguardia, 22 de abril. Disponible en: http://hemeroteca-paginas.lavanguardia.com/LVE08/HEM/1989/04/22/LVG19890422006.pdf

Descola, Philippe (2012) Más allá de la naturaleza y la cultura. Buenos Aires: Amorrortu Ediciones.

Despret, Vinciane (2013) "Responding Bodies and Parital Affinities in Human-Animal Worlds”, Theory, Culture \& Society, 30(7-8): 51-76.

Digard, Jean-Pierre (1990) L'homme et Les Anumauxs Domestiques: Anthopologie d'une Passion. Paris: Fayard.

Dizard, Jan E. (1994) Going Wild: Hunting, Animal Rights, and the Contested Meaning of Nature. Amherst: University of Massachusetts Press.

D.J.M.G.N. (1790) El experimentado cazador y el perfecto tirador. Madrid: Oficina Aznar.

Favareau, Donald (2010) Essential Readings in Biosemiotics. Anthology and commentary. Vol. 3. London: Springer.

Fernández de Moratín, Francisco (1765) La Diana, o Arte de la caza. Madrid: Oficina de Miguel Escribano.

Florido del Corral, David, y Palenzuela, Pablo (2017) "Valores culturales, discursos y conflictos en torno a la caza. El caso de las monterías sociales en Andalucía”. Revista Andaluza de Antropología, 13: 53-84.

Gamuz, Helena P. (2021) "Etnografía de las relaciones humano-animales en el contexto de la caza de liebres con galgos en Fuentes de Andalucía (Sevilla)". Trabajo de Fin de Máster, Universidad de Sevilla.

Ginzburg, Carlo (1989) Mitos, emblemas, indicios, Barcelona: Gedisa.

Gómez Pellón, Eloy (2017) “Los problemas del patrimonio inmaterial: uso y abuso de los animales en España”. Revista de Antropología Iberoamericana, 12(2): 147-168.

Harrison, Rodney (2013) Heritage: Critical Approaches. Londres: Routledge. 
Hernández-Ramírez, Javier (2007) "El patrimonio activado. Patrimonialización y movimientos sociales en Andalucía y ciudad de México". Dimensión Antropológica, 14(41): 7-44.

Kuhl, Gail (2011) "Human-Sled Dog Relations: What Can We Learn From the Stories and Experiences of Muchers?", Society \& Animals, 19 (1): 22-37.

Ley 8/2003, de 28 de octubre, de la Flora y la Fauna Silvestre. Boletín Oficial del Estado 288.

Ley 18/2013, de 12 de noviembre, para la regulación de la tauromaquia como patrimonio cultural. Boletín Oficial del Estado 272.

López Ontiveros, Antonio (1994) "Caza, actividad agraria y geografía de España". Documents d’analisi Geográfica, 24: 111-130.

-_- (Coord.) (2003) Geografía de Andalucía. Barcelona: Ariel.

Marvin, Garry (2005) “Guest Editor's Introduction: Seeing, Looking, Watching, Observing Nonhuman Animals”. Society \& Animals, 13(I): 1-12.

Ortega y Gasset, José (1962) La caza y los toros. Madrid: Espasa-Calpe.

Palacios, Fernando y Mejide, Manuel (1979) "Distribución geográfica y hábitat de las liebres en la Península Ibérica”. Naturalia Hispanica, 19: 1-40.

Palenzuela, Pablo (1996) Buscarse la vida. Economía jornalera en las marismas de Sevilla. Sevilla: Área de Cultura del Ayuntamiento de Sevilla.

Palenzuela, Pablo, y Hernández, Javier (1995) Poner Monachil en el mapa. Estudio antropológico de un proceso de transformación cultural. Granada: Universidad de Granada y Diputación de Granada.

Quintero Morón, Victoria (2009) Los sentidos del patrimonio: alianzas y conflictos en la construcción del patrimonio etnológico andaluz. Fundación Blas Infante. Sevilla.

Romero, Antonio (2014) Cien años de deporte galguero en nuestra tierra. En Federación Andaluza de Galgos (ed.), Un siglo de galgos. Catálogo de la Exposición Conmemorativa del Centenario de la Copa La Ina, pp. 7-8. Sevilla: Altagrafics. (2011). Los siete galgueros de Écija. Málaga: Ed. Carmen Morillo. (2010). El gran libro de los galgos. Sevilla: Editorial Almuzara.

Rengifo, Juan Ignacio, y Sánchez Martín, José Manuel (2016) “Caza y espacios naturales protegidos en Extremadura”. Investigaciones Geográficas, 65: 57-73. 
Riqueni Barrios, José (2012) Días de caza menor. Vida y caza de la liebre. Tertulias cinegéticas y añoranzas. Sevilla: Espuela de Plata.

Robinson, Lisa, y Watkinson Julie (2020) "Galgos and Podencos in Spain: A Rescue's Perspective". Journal of Applied Animal Ethics Research, 2: 69-75.

Salamanca, Francisco (2010) "Cosas de galgos". En Antonio Romero (ed.), El gran libro de los galgos. Sevilla: Editorial Almuzara. pp. 192-196.

Seiru-lo Soares, Francisco (1978) Galgos y liebres. Su caza, espectáculo de llanura. Salamanca: Imprenta Núñez.

Sánchez Carretero, Cristina (2017) "Hacia una antropología del conflicto aplicada al patrimonio". En Beatriz Santamarina Campos (coords.) Geopolíticas patrimoniales: de culturas, naturalezas e inmaterialidades: una mirada etnográfica. Valencia: Neopátria pp. 215-230.

Sánchez Garrido, Roberto (2007) “Actividad Humana y naturaleza. La práctica cinegética y los usos del medio natural. El caso del parque natural de la sierra del carrascal de la Font Roja”. Tesis Doctoral. Universidad de Murcia, Murcia

Sánchez Gascón, Alonso (2007) Leyes históricas de caza. Madrid. Exlibris.

Santamarina, Beatriz, y Del Mármol, Camila. (2020) “Para algo que era nuestro... ahora es de toda la humanidad': el patrimonio mundial como expresión de conflictos". Chungará (Arica), 52(1): 161-173.

Signer, Peter (1975) Animal Liberation: A New Ethincs for our Tretament of Animals. New York. New York Review.

Smith, Laurajane (2006) Uses of Heritage. Routledge, Nueva York.

Uexküll, Jakob J. [1934] (2016) Andanzas por los mundos circundantes de los animales y los hombres. Buenos Aires: Cactus.

UNESCO (2003) Convención para la Salvaguardia del Patrimonio Cultural Inmaterial. París: UNESCO.

V.V.A.A. (1858) Tesoro de los perros de caza: o sea Arte de conocer las razas de perros, elección de los de caza, modo de criarlos, enseñarlos, adiestrarlos y curar sus enfermedades, con los secretos y recetas para el pronto alivio de sus males. Madrid: Imprenta de D. Ramón Campuzano. 
Zuppi, Andrea (2017) "Naturalism and the representation of animals in the Southern French Pyrenees". Anuac. Vol., Revista della Società Italiana di Antropologia Culturale, 6(2): 129-154. 